\title{
Investigations Into the Reusability of Amidoxime-Based Polymeric Uranium Adsorbents
}

\section{September 2016}

Li-Jung Kuo, Gary A Gill, Jonathan Strivens, Jordana Wood and Nicholas Schlafer, Pacific Northwest National Laboratory, Marine Sciences Laboratory, Sequim, WA 98382

Chien M. Wai, University of Idaho, Moscow, Idaho 83844 and LCW Supercritical Technologies, LLC, Seattle, WA 98103

Horng-Bin Pan, University of Idaho, Moscow, Idaho 83844 


\section{DISCLAIMER}

This report was prepared as an account of work sponsored by an agency of the United States Government. Neither the United States Government nor any agency thereof, nor Battelle Memorial Institute, nor any of their employees, makes any warranty, express or implied, or assumes any legal liability or responsibility for the accuracy, completeness, or usefulness of any information, apparatus, product, or process disclosed, or represents that its use would not infringe privately owned rights. Reference herein to any specific commercial product, process, or service by trade name, trademark, manufacturer, or otherwise does not necessarily constitute or imply its endorsement, recommendation, or favoring by the United States Government or any agency thereof, or Battelle Memorial Institute. The views and opinions of authors expressed herein do not necessarily state or reflect those of the United States Government or any agency thereof.

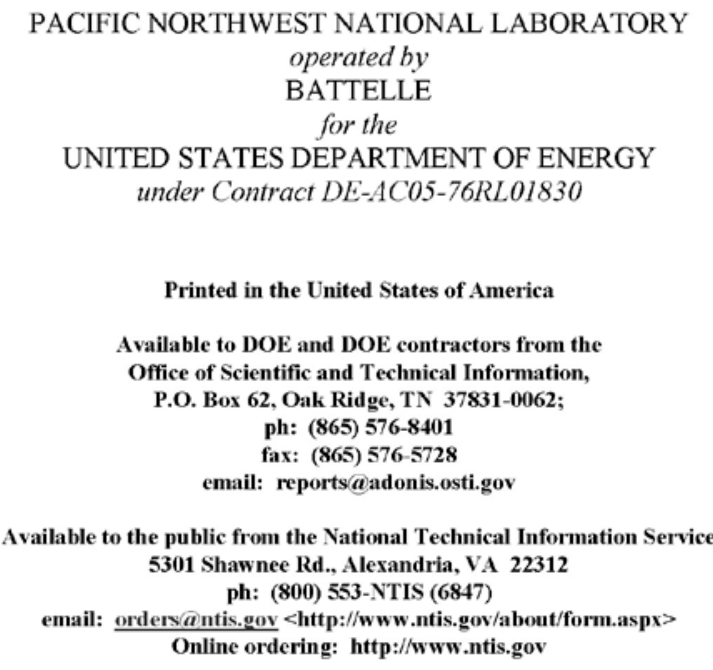


PNNL-25874

\section{Investigations Into the Reusability of Amidoxime-Based Polymeric Uranium Adsorbents}

Prepared for: U. S. Department of Energy, Office of Nuclear Energy, Fuel Cycle Research and Development Program, Fuel Resources Program

Prepared by: Li-Jung Kuo, Gary A Gill, Jonathan Strivens, Jordana Wood and Nicholas

Schlafer, Pacific Northwest National Laboratory, Marine Sciences Laboratory

Sequim, WA 98382

Chien M. Wai, University of Idaho, Moscow, Idaho 83844 and LCW

Supercritical Technologies, LLC, Seattle, WA 98103

Horng-Bin Pan, University of Idaho, Moscow, Idaho 83844

Milestone Number: M3FT-16PN030201047

Work Package Number: FT-16PN03020104

Milestone Due Date: September 30, 2016

U. S. DOE-NE Program Manager: Dr. Stephen Kung

Milestone Level: M3

PNNL Information Release Number: PNNL-25874

Prepared for the U.S. Department of Energy under Contract

DE-AC05-76RL01830, Pacific Northwest National Laboratory, Richland,

Washington 99352 


\section{Executive Summary}

Significant advancements in amidoxime-based polymeric adsorbents to extract uranium from seawater are achieved in recent years. The success of uranium adsorbent development can help provide a sustainable supply of fuel for nuclear reactors. To bring down the production cost of this new technology, in addition to the development of novel adsorbents with high uranium capacity and manufacture cost, the development of adsorbent re-using technique is critical because it can further reduce the cost of the adsorbent manufacture. In our last report, the use of high concentrations of bicarbonate solution $\left(3 \mathrm{M} \mathrm{KHCO}_{3}\right)$ was identified as a cost-effective, environmental friendly method to strip uranium from amidoxime-based polymeric adsorbents. This study aims to further improve the method for high recovery of uranium capacity in re-uses and to evaluate the performance of adsorbents after multiple re-use cycles.

Adsorption of dissolved organic matter (DOM) on the uranium adsorbents during seawater exposure can hinder the uranium adsorption and slow down the adsorption rate. An additional $\mathrm{NaOH}$ rinse $\left(0.5 \mathrm{M} \mathrm{NaOH}\right.$, room temperature) was applied after the $3 \mathrm{M} \mathrm{KHCO}_{3}$ elution to remove natural organic matter from adsorbents. The combination of $3 \mathrm{M} \mathrm{KHCO}_{3}$ elution and 0.5 $\mathrm{M} \mathrm{NaOH}$ rinse significantly improves the recovery of uranium adsorption capacity in the re-used adsorbents. In the first re-use, most ORNL adsorbents tested achieve $\sim 100 \%$ recovery by using $3 \mathrm{M} \mathrm{KHCO}_{3}$ elution $+0.5 \mathrm{M} \mathrm{NaOH}$ rinse approach, in comparison to $54 \%$ recovery when only 3 $\mathrm{M} \mathrm{KHCO}_{3}$ elution was applied.

A significant drop in capacity was observed when the adsorbents went through more than one re-use. FTIR spectra revealed that degradation of amidoxime ligands occurs during seawater exposure, and is more significant the longer the exposure time. Significantly elevated ratios of $\mathrm{Ca} / \mathrm{U}$ and $\mathrm{Mg} / \mathrm{U}$ in re-used adsorbents support the decrease in abundance of amidoxime ligands and increase carboxylate group from FT-IR analysis.

The impact of the length of seawater exposure cycle in adsorbent re-use was evaluated by comparing the adsorption capacity for a common adsorbent formulation (ORNL AI8 formulation) under different exposure cycle (28 days and 42 days). Adsorbents with a 28 days seawater exposure cycle had higher recovery of uranium capacity than adsorbent with 42 days of seawater exposure. Under different cumulative seawater exposure time, the adsorbent with 28 days seawater exposure cycle also had less amidoxime ligands degradation than the adsorbent with 42 days seawater exposure cycle. These observations support the negative impact of prolonged seawater exposure on amidoxime ligands stability. Recovery of uranium capacity in re-uses also varies across different adsorbent formulations. Among three different ORNL adsorbents tested (AI8, AF8, AF1-DMSO), AI8 had the best recovery in each re-use, followed by AF8 and then AF1-DMSO. This demonstrates that continuing efforts on developing new adsorbents with high capacity and stability is critical. 
The overall performance of adsorbents in multiple re-use cycles can be evaluated by calculation total harvestable uranium, the summation of adsorbed uranium from each seawater exposure cycle. In this assessment, the ORNL AI8 braid with 28 days seawater exposure cycle can reach total harvestable uranium $10 \mathrm{~g}$ Uranium $/ \mathrm{kg}$ adsorbent in $\sim 140$ days; while the same type of braid but with 42 days seawater exposure cycle reach the same level in $~ 170$ days. Notably, the performance of total harvestable uranium also varies among different adsorbent formulations (AI8 > AF1-DMSO > AF8). Short seawater exposure cycle is associated with high re-use frequency. The development of low-cost offshore adsorbent deployment/extraction is essential for high frequency reuse operation. This study also highlights the importance to examine the re-use performance of newly developed uranium adsorbents for selection of optimal adsorbents for ocean deployment. 


\section{Acronyms and Abbreviations}

$\begin{array}{ll}\text { DOE } & \text { U.S. Department of Energy } \\ \text { DOE-NE } & \text { U.S. Department of Energy, Office of Nuclear Energy } \\ \text { DOM } & \text { Dissolved Organic Matter } \\ \text { DOC } & \text { Dissolved Organic Carbon } \\ \text { FTIR } & \text { Fourier Transform Infrared Spectroscopy } \\ \text { ICP-MS } & \text { Inductively Coupled Plasma Mass Spectrometry } \\ \text { ICP-OES } & \text { Inductively Coupled Plasma Optical Emission Spectrometry } \\ \text { LCW } & \text { LCW Supercritical Technologies, LLC } \\ \text { MSL } & \text { Marine Sciences Laboratory } \\ \text { ORNL } & \text { Oak Ridge National Laboratory } \\ \text { OSLSM } & \text { One-Site Ligand Saturation Modeling } \\ \text { PNNL } & \text { Pacific Northwest National Laboratory } \\ \text { RIGP } & \text { Radiation Induced Graft Polymerization }\end{array}$




\section{Contents}

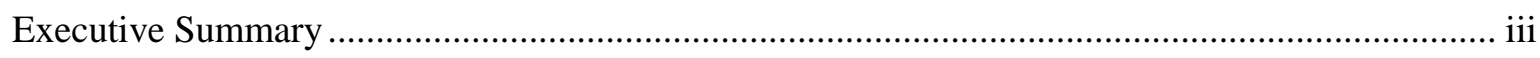

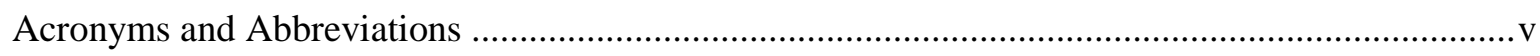

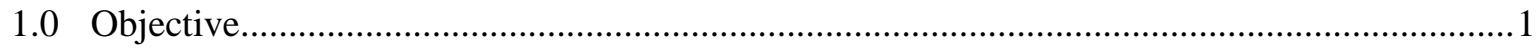

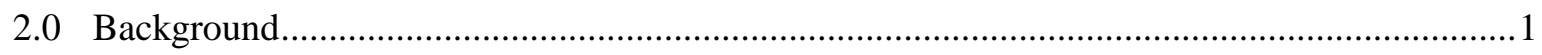

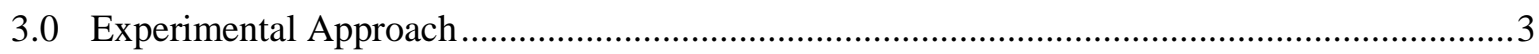

3.1 Ambient Seawater Exposure Systems at PNNL............................................................

3.2 Water Quality, Temperature and Flow-rate Monitoring ..............................................

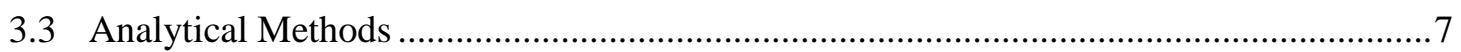

3.3.1 Determination of Uranium and Trace Elements on Adsorbent Materials ................7

3.3.2 Determination of Uranium and Other Elements in Seawater ................................

3.3.3 Fourier Transform Infrared Spectroscopy (FTIR) Analysis...................................

3.4 One-Site Ligand Saturation Modeling ...........................................................................

3.5 Recycling Approaches for Re-use of Amidoxime-Based Uranium Adsorbents ..............10

3.5.1 Recycling Approach: Bicarbonate - NaOH Coupled Elution................................10

3.6 Preparation of Amidoxime-based Polymeric Adsorbent Braids ......................................10

3.7 Multi-cycle Adsorbent Re-use Test............................................................................ 11

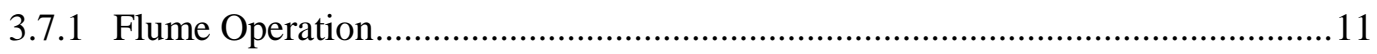

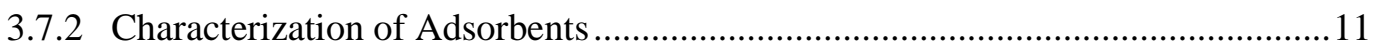

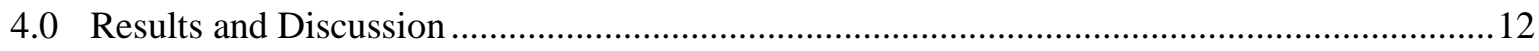

4.1 Improvement of Adsorbent Reusability by Organic Matter Removal .............................12

4.2 Adsorbent Reusability Performance After Multi-Reuse Cycles ....................................... 14

4.2.1 Reusability of the ORNL Adsorbent Formulation AI8 ......................................14

4.2.2 Reusability of the ORNL Adsorbent Formulation AF1 …...................................17

4.3 Effects of seawater exposure time and adsorbent types on adsorbent reusability ............19

4.3.1 Simultaneous Reusability Test with Three Different Amidoxime-based Adsorbent Formulations .............................................................................22

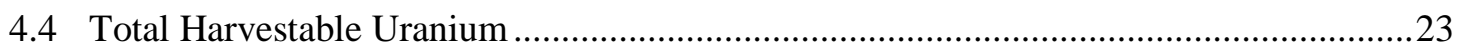

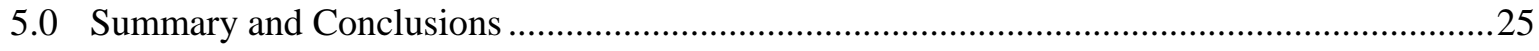

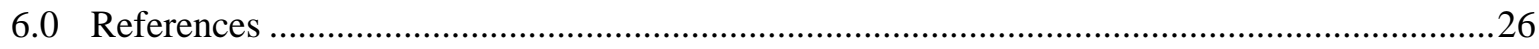




\section{Figures}

Figure 1. Comparison of $\mathrm{U}$ adsorption capacity for ORNL AF1 adsorbent fibers treated with $\mathrm{NaOH}$ after the first reuse (red bar) with results obtained from the $3 \mathrm{M} \mathrm{KHCO}_{3}$ elution/recycling experiment (blue columns). The percentage numbers above the columns are percentage recovery of $U$ adsorption capacity relative to the adsorption capacity of the $1^{\text {st }}$ re-used adsorbent.

Figure 2. Side view depiction of the recirculating flume system used for exposing braided adsorbent material to filtered or unfiltered natural seawater under controlled temperature and flow-rate (linear velocity) conditions. Six braided adsorbent materials are depicted within the flume. An external pump is used to recirculate seawater in the flume. The linear velocity in the flume is controlled by a restriction on the exit of the pump. Fresh seawater is fed into the flume from a temperature controlled reservoir at a fixed rate. Seawater rises in the flume to the height of the overflow tube and then spills out at the same rate as it is introduced from the head tank.

Figure 3. Flumes used for studying the effect of linear velocity on adsorption performance. The flume on the left is the $8 \mathrm{ft}$. flume (Flume B) and the flume on the right is the $6 \mathrm{ft}$. flume (Flume C) that is described in Table 2. The recirculation pump for flume $\mathrm{C}$ is shown in the lower left side of the picture. The inlet for fresh seawater is introduced through the $1 / 2$ inch poly tubing on the near side of the flumes.

Figure 4. Adsorbent braid attached to a short length of 1/4-inch diameter polyethylene tubing. The tubing end is inserted into a PVC block attached to the bottom of the flume, fixing the braid in the flume in the desired exposure position.

Figure 5. ThermoNicolet 6700 ATR-FTIR spectrometer .............................................................

Figure 6. FTIR spectrum of the AF1L2R3 sorbent after conditioning with $2.5 \% \mathrm{KOH}$ solution at $80{ }^{\circ} \mathrm{C}$ for 1 hour.

Figure 7. Comparison of uranium adsorption kinetics of two ORNL AI8 braids during initial seawater exposure and re-exposure after $\mathrm{KHCO}_{3}+\mathrm{NaOH}$ treatment: (a) an ORNL AI8 braid tested in 28-day seawater exposure cycle; (b) an ORNL AI8 braid tested in 42-day seawater exposure cycle.

Figure 8. Comparison of FT-IR spectra of an ORNL AI8 adsorbent in sequential treatments: before seawater exposure, after 28-day seawater exposure, after $\mathrm{KHCO}_{3}$ elution, and after the $\mathrm{NaOH}$ rinse, respectively.

Figure 9. Uranium adsorption kinetics of an ORNL AI8 braid that was subjected to five, 28-day exposure, adsorption/stripping cycles. All data were normalized to a salinity of 35. The kinetics data were modeled using one-site ligand saturation modeling.

Figure 10. Comparison of FT-IR spectra of an ORNL AI8 braid underwent a 28-day initial seawater exposure followed by re-exposures after the $\mathrm{KHCO}_{3}+\mathrm{NaOH}$ elution. The Each spectrum was from a braid snip sampled at a specific time point during the course of seawater exposure. The spectra were stacked from bottom to top with increasing seawater exposure time...

Figure 11. Changes of ratios of Ca, Mg vs. U from braid snips collected in the end of each seawater exposure during the recycling study of an ORNL AI8 braid. Each cycle of the seawater exposure is 28 days. Before each seawater re-exposure, the braid was treated with $\mathrm{KHCO}_{3}+\mathrm{NaOH}$ elution to remove uranium and other elements, including $\mathrm{Ca}$ and $\mathrm{Mg}$. . 
Figure 12. Time course FT-IR spectra of an ORNL AF1 braid after a 56-day initial seawater exposure (left panel) followed by re-exposure to seawater after the $\mathrm{KHCO}_{3}+\mathrm{NaOH}$ elution steps (right panel). Each spectrum was from a braid snip sampled at a specific time point during the course of the seawater exposures.

Figure 13. Time course changes in the FT-IR intensity of the $928 \mathrm{~cm}^{-1}(\mathrm{~N}-\mathrm{O}$ stretching) peak obtained during a 56-day exposure of the ORNL AF1 braid. Before seawater re-exposure, the braid was treated with $\mathrm{KHCO}_{3}+\mathrm{NaOH}$ elution to remove uranium and adsorbed natural organic matter.

Figure 14. Changes of ratios of Ca, Mg vs. U from braid snips collected in the end of each seawater exposure during a recycling study with an ORNL AF1 braid. Each cycle of the seawater exposure is 56 days. Before each seawater re-exposure, the braid was treated with $\mathrm{KHCO}_{3}+\mathrm{NaOH}$ elution to remove uranium and other elements, including Ca and Mg.

Figure 15. Recovery of uranium adsorption capacity of two ORNL AI8 braids in re-uses. One braid was on 28 days seawater exposure cycle (four re-uses were conducted); another was on 42 days seawater exposure cycle (three re-uses were conducted). $\mathrm{KHCO}_{3}$ elution $+\mathrm{NaOH}$ rinse were used to remove uranium and organic matter from braids before re-uses. ................20

Figure 16. Recovery of uranium adsorption capacity as a function of cumulative seawater exposure time of two ORNL AI8 braids. One adsorbent was on a 28-day seawater exposure cycle and the other was on a 42-day seawater exposure cycle. $\mathrm{A} \mathrm{KHCO}_{3}$ elution $+\mathrm{NaOH}$ rinse was used to remove uranium and organic matter from the braids before re-use.

Figure 17. Percentage of peak intensity of $928 \mathrm{~cm}^{-1}(\mathrm{~N}-\mathrm{O}$ stretching) from FT-IR as a function of cumulative seawater exposure time of two ORNL AI8 braids. One adsorbent was on a 28day seawater exposure cycle and the other was on a 42-day seawater exposure cycle. A $\mathrm{KHCO}_{3}$ elution $+\mathrm{NaOH}$ rinse was used to remove uranium and organic matter from the braids before re-use.

Figure 18. Comparison of recovery of uranium adsorption capacity of three ORNL braids with different formulations (AI8, AF8, AF1-DMSO) in multiple re-uses. All three braids were tested simultaneously using a 28-day seawater exposure cycle.

Figure 19. Total harvestable uranium (g/kg) vs. cumulative seawater exposure time of four ORNL braided adsorbents, different in formulation (AI8, AF8, AF1-DMSO) or seawater exposure cycle (28 days and 42 days. The total harvestable uranium is a cumulative adsorbed uranium from each seawater deployment.

\section{Tables}

Table 1. One-site ligand saturation modeling of time-dependent measurements of an ORNL AF1 braid recycled using $3 \mathrm{M} \mathrm{KHCO}_{3}$ elution. The braid was deployed in a seawater flume at $20^{\circ} \mathrm{C}$ in 42 days exposure cycle. All data were normalized to a salinity of $35 \mathrm{psu}$.

Table 2. Estimated dissolved organic carbon (DOC) content removed from three separate seawater-exposed ORNL braids by $\mathrm{NaOH}$ rinsing.

Table 3 FT-IR signatures (ratio of $\mathrm{I}_{1643} / \mathrm{I}_{1559}$, peak intensity of $\mathrm{I}_{928}$ ) of an ORNL AI8 adsorbent under sequential treatments. The FT-IR spectra were shown in Figure 10. 
PNNL-25874

Table 4 One-site ligand saturation modeling of time-dependent measurements of an ORNL AI8 braid subjected to five, 28-day exposure, adsorption/stripping cycles. All data were normalized to a salinity of 35 . 


\subsection{Objective}

The Pacific Northwest National Laboratory (PNNL) has a level 3 milestone (M3FT16PN030201047) due on September 30, 2016 to optimize the bicarbonate elution process for extraction of uranium from amidoxime-based adsorbents. This report is a continuing effort of a prior level 2 milestone report (M2FT-15PN0310051) entitled "Demonstrate the alternative desorption agents that can effectively remove uranium from adsorbent materials under natural seawater conditions". In the present report, an improved uranium desorption method was developed to efficiently strip uranium from amidoxime-based adsorbents. Specific attention is addressed to adsorbent performance in multiple loading/stripping cycles under real seawater conditions. Performance parameters which were evaluated included: (1) length of seawater exposure time; (2) performance of different adsorbent formulations; (3) stability of amidoxime ligands to repeated loading/stripping cycles and seawater exposure time.

\subsection{Background}

The U. S. Department of Energy, Office of Nuclear Energy, Fuel Resources Program is developing adsorbent technology to extract uranium from seawater. The need for development of this technology is to provide a sustainable and economically viable supply of uranium fuel for nuclear reactors (U.S Department of Energy, 2010). A key component in the development of this technology is the ability to reuse the adsorbent material repeatedly through multiple deployment/uranium stripping cycles (Lindner and Schneider, 2015). Among three major components in the cost analysis (adsorbent production, deployment, and extraction), adsorbent production is usually the major cost in the seawater extraction process. Efficient re-use of an adsorbent can significantly lower the overall cost of producing uranium from a seawater resource (Schneider and Sachde, 2013).

In our prior report on adsorbent reusability, three adsorbent elution methods, diluted acid leaching followed by $\mathrm{KOH}$ re-conditioing, $\mathrm{KHCO}_{3}$ elution, and $\mathrm{KHCO}_{3}$ elution followed by tiron elution, were critically evaluated by using several ORNL amidoxime-based polymeric adsorbents (Gill et al., 2015). We found that the ORNL amidoxime-based adsorbents had a significant loss of uranium adsorption capacity when dilute acid was used to strip off the uranium and other adsorbed elements, followed by $\mathrm{KOH}$ re-conditioning for re-use. This process resulted in degradation of amidoxime ligands and also physically damaged the adsorbent. $\mathrm{KHCO}_{3}$ elution, on the other hand, is a mild uranium elution method and was shown to be very selective for removing $U$ from amidoxime-based adsorbents. The recovery of uranium adsorption capacity after re-use by using $\mathrm{KHCO}_{3}$ elution, however, was still not ideal (54\% recovery with the first re-use). Adding a tiron rinse to the scheme, which removes iron from the adsorbent, did not improve recovery for uranium. Nevertheless, the discovery of 
$\mathrm{KHCO}_{3}$ elution as a novel, environmental friendly uranium stripping method still holds great promise.

Another major finding of the previous work was that the uranium adsorption rate of the ORNL AF1 braid decreased with re-use with the $\mathrm{KHCO}_{3}$ elution method. One-site ligand saturation modeling shows that the half-saturation time of the re-used adsorbent is three times longer than that of the new adsorbent, while the saturation capacity of re-used adsorbent and the new adsorbent are comparable (Table 1). We hypothesized that the slowdown of uranium adsorption rate may be related to the adsorption of dissolved natural organic matter (NOM) on the uranium adsorbent during seawater exposure, as dissolved organic matter (DOM) is ubiquitous in natural waters and can’t be removed by 0.45 um filtration.

Table 1. One-site ligand saturation modeling of time-dependent measurements of an ORNL AF1 braid recycled using $3 \mathrm{M} \mathrm{KHCO}_{3}$ elution. The braid was deployed in a seawater flume at $20^{\circ} \mathrm{C}$ in 42 days exposure cycle. All data were normalized to a salinity of $35 \mathrm{psu}$.

\begin{tabular}{cccc}
\hline $\begin{array}{c}\text { Seawater } \\
\text { exposure cycle }\end{array}$ & $\begin{array}{c}\text { Residual uranium } \\
\text { after leaching } \\
\text { (g U/ kg adsorbent) }\end{array}$ & $\begin{array}{c}\text { Half-Saturation } \\
\text { Time (days) }\end{array}$ & $\begin{array}{c}\text { Saturation Capacity } \\
\text { (g U/ kg adsorbent) }\end{array}$ \\
\hline Initial & 0.36 & $16.9 \pm 1.67$ & $5.20 \pm 0.20$ \\
\hline $1^{\text {st }}$ re-use & 0.25 & $57.7 \pm 14.6$ & $4.70 \pm 0.78$ \\
\hline
\end{tabular}

A preliminary test was then conducted to examine the potential effect of DOM adsorption on the reusability performance of the uranium adsorbent. In addition to $\mathrm{KHCO}_{3}$ elution, a $0.5 \mathrm{M}$ $\mathrm{NaOH}$ rinse was applied to some braid snips taken from an ORNL AF1 braid that had undergone 42 days of seawater exposure to remove organic matter adsorbed on the uranium adsorbent. The $\mathrm{NaOH}$ treatment is considered a simple, mild way for NOM removal since humic acid (a major component in NOM) can dissolve in the alkaline solution and amidoxime ligands arestable in alkaline solution at room temperature (Kang et al., 2012). Comparison of uranium capacity of the re-deployed $\mathrm{KHCO}_{3}$ treated adsorbent and the $\mathrm{KHCO}_{3}+\mathrm{NaOH}$ treated adsorbent show that the adsorbent treated with the $\mathrm{NaOH}$ rinse had a higher $\mathrm{U}$ adsorption capacity (33\% higher) than those that received no $\mathrm{NaOH}$ treatment (Figure 1). This test provides the first evidence that adsorption of DOM from seawater onto the adsorbent material during extended seawater exposure may be influencing $\mathrm{U}$ adsorption capacity. 


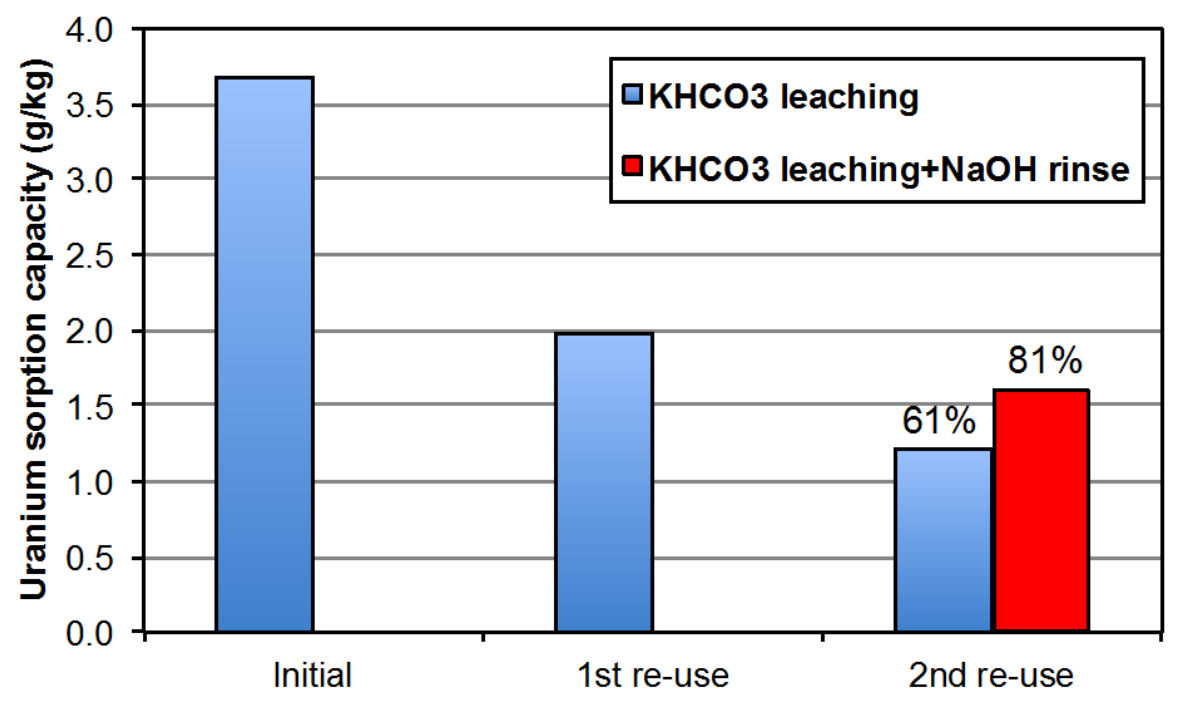

Figure 1. Comparison of $U$ adsorption capacity for ORNL AF1 adsorbent fibers treated with NaOH after the first reuse (red bar) with results obtained from the $3 \mathrm{M} \mathrm{KHCO}_{3}$ elution/recycling experiment (blue columns). The percentage numbers above the columns are percentage recovery of $U$ adsorption capacity relative to the adsorption capacity of the $1^{\text {st }}$ re-used adsorbent.

In the present study, we conducted an in-depth evaluation of the modified uranium stripping method: $\mathrm{KHCO}_{3}$ elution $+\mathrm{NaOH}$ rinse. ORNL adsorbents were subjected to several adsorption/stripping cycles to understand the change of recovery of uranium adsorption capacity with re-use. The performance of different ORNL adsorbent formulations and effect of different seawater exposure times was also investigated. Information from both spectroscopic analysis and elemental distribution were used to help elucidate the causes of change in adsorbent reusability. The ultimate goal is to find an optimal loading/stripping procedure and associated deployment time that yields the most uranium from seawater, thereby lowering operational costs.

\subsection{Experimental Approach}

Amidoxime-based polymeric braid adsorbents were deployed in a flume system exposed to ambient filtered seawater at $20^{\circ} \mathrm{C}$ for a multi-cycle adsorbent re-use study. Stripping of uranium from the braids for re-use was conducted using the sequential potassium bicarbonate and $\mathrm{NaOH}$ elution scheme that was developed previously. Adsorption kinetics and adsorption capacity were assessed using time series determinations of uranium adsorption and one-site ligand saturation modeling. Adsorbents were further characterized by FTIR spectroscopic measurements to investigate potential chemical alterations of adsorbent materials after seawater exposure and adsorbent recycling. 


\subsection{Ambient Seawater Exposure Systems at PNNL}

Marine testing was conducted at the Marine Sciences Laboratory (MSL), a coastal based marine laboratory within PNNL, using ambient seawater from Sequim Bay, WA. The MSL has a seawater delivery system that can provide ambient seawater into a "wet laboratory" for scientific investigations. Ambient seawater is drawn by pump from a depth of $\sim 10 \mathrm{~m}$ from Sequim Bay through a plastic pipe. Raw seawater is pumped directly into the laboratory for use. Filtered seawater is obtained by first passing raw seawater through an Arkal Spin Klin ${ }^{\mathrm{TM}}$ filter system (nominal pore size $40 \mu \mathrm{m}$ ) to remove large particles. The partially filtered seawater is then stored in a large volume ( 3,500 gal) reservoir tank outside the laboratory. This seawater is gravity fed into the laboratory research facilities through PVC piping where it can be passed through additional filtration to remove finer particles if needed at the point of use. Additional details about the seawater exposure system at PNNL are given in Gill et al. (2016).

The Pacific Northwest National Laboratory has developed flow-through channels for conducting flume experiments under controlled temperature and flow-rate conditions. Different size pumps and flume dimensions are used to create a range in flow-rate (linear velocity). The flumes were constructed with different dimensions and recirculating pump sizes for conducting exposure tests with braided adsorbent material under controlled temperature and flow-rate (linear velocity) conditions. The target linear velocity is $2 \mathrm{~cm} / \mathrm{sec}$, which is approximately the linear velocity being used for testing with flow-through columns at PNNL (Gill et al., 2016). The flumes were constructed of darkened acrylic material to limit biological growth.

Shown in Figure 2 is a cross sectional view of the flume design illustrating the recirculation system and seawater inlet. A picture of the three flumes is shown in Figure 3. Fresh seawater is fed into the flume at flow-rates up to $5 \mathrm{~L} / \mathrm{min}$ using the seawater manifold delivery system described in Gill et al (2016). A tubing line was run from one or more of the manifold ports directly into the flume to achieve the desired seawater delivery rates. The rate of fresh seawater delivery was controlled using a needle valve mounted on one or more ports in the manifold. The height of water in the flume is controlled by the height of the stand pipe, which can be varied between approximately 7 and 11 inches $(18-28 \mathrm{~cm})$. Water within the flume rises until it reaches the height of the standpipe and then spills out of the flume through the standpipe. Raising or lowering the water height changes the cross sectional area of the water in the flume, which in turn is a means to control the linear velocity in the flume.

Braided adsorbents were placed into the flumes for exposure by attaching them to a short length of $1 / 4$ inch polyethylene tubing with cable ties and inserting one end of the tubing into a small block mounted on the bottom of the flume into which a $1 / 4$ inch hole has been drilled (Figure 4).

The rate at which fresh seawater is fed into the system and the internal volume of the flume controls the residence time of seawater in the system. For example, with the $6 \mathrm{ft}$. flume, the 
water residence time is $\sim 20$ minutes. The time to recirculate water is much faster. At a recirculation flow rate of $87 \mathrm{~L} / \mathrm{min}$, the water in the flume is recirculated once every 24 seconds.

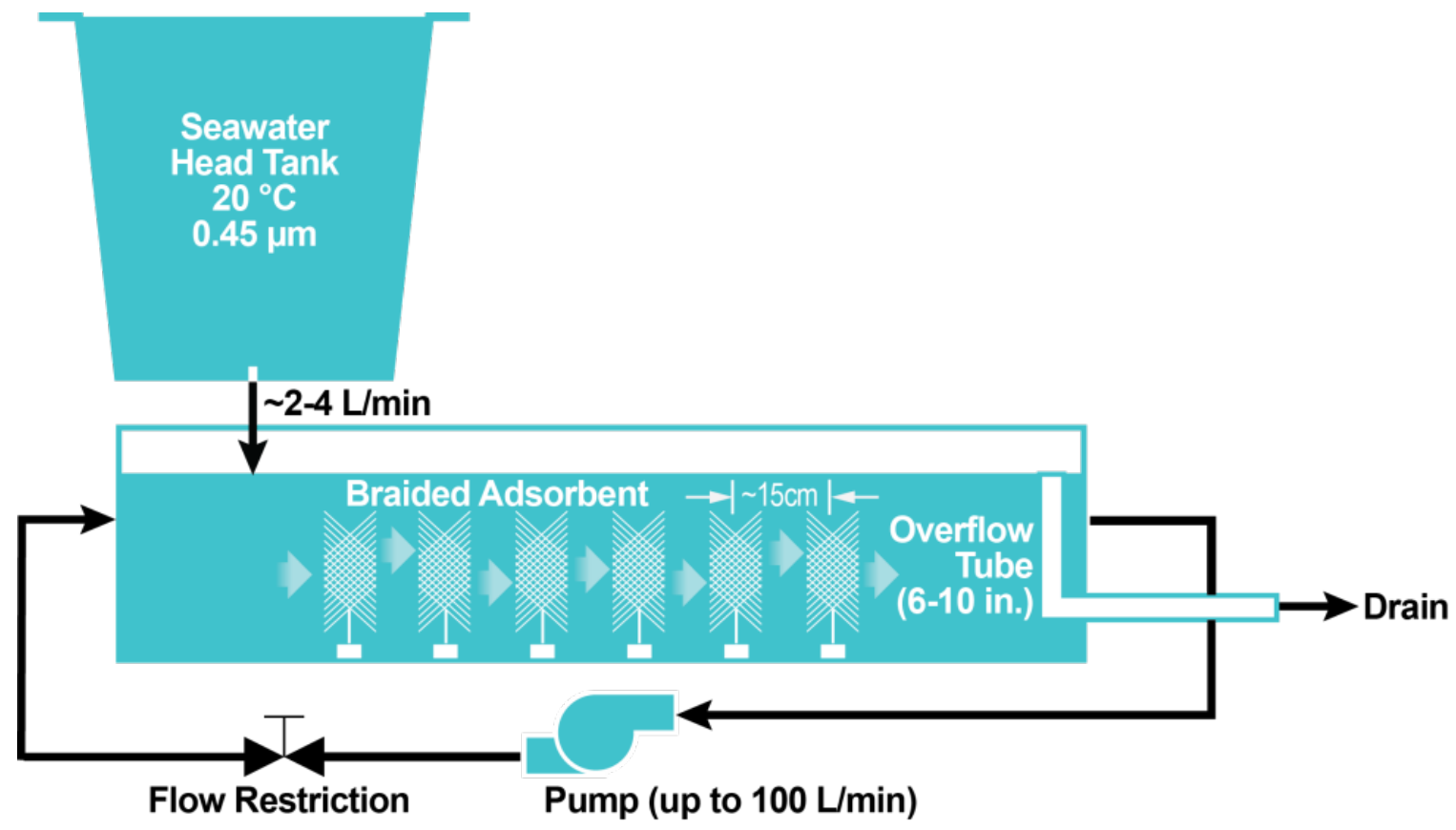

Figure 2. Side view depiction of the recirculating flume system used for exposing braided adsorbent material to filtered or unfiltered natural seawater under controlled temperature and flow-rate (linear velocity) conditions. Six braided adsorbent materials are depicted within the flume. An external pump is used to recirculate seawater in the flume. The linear velocity in the flume is controlled by a restriction on the exit of the pump. Fresh seawater is fed into the flume from a temperature controlled reservoir at a fixed rate. Seawater rises in the flume to the height of the overflow tube and then spills out at the same rate as it is introduced from the head tank. 


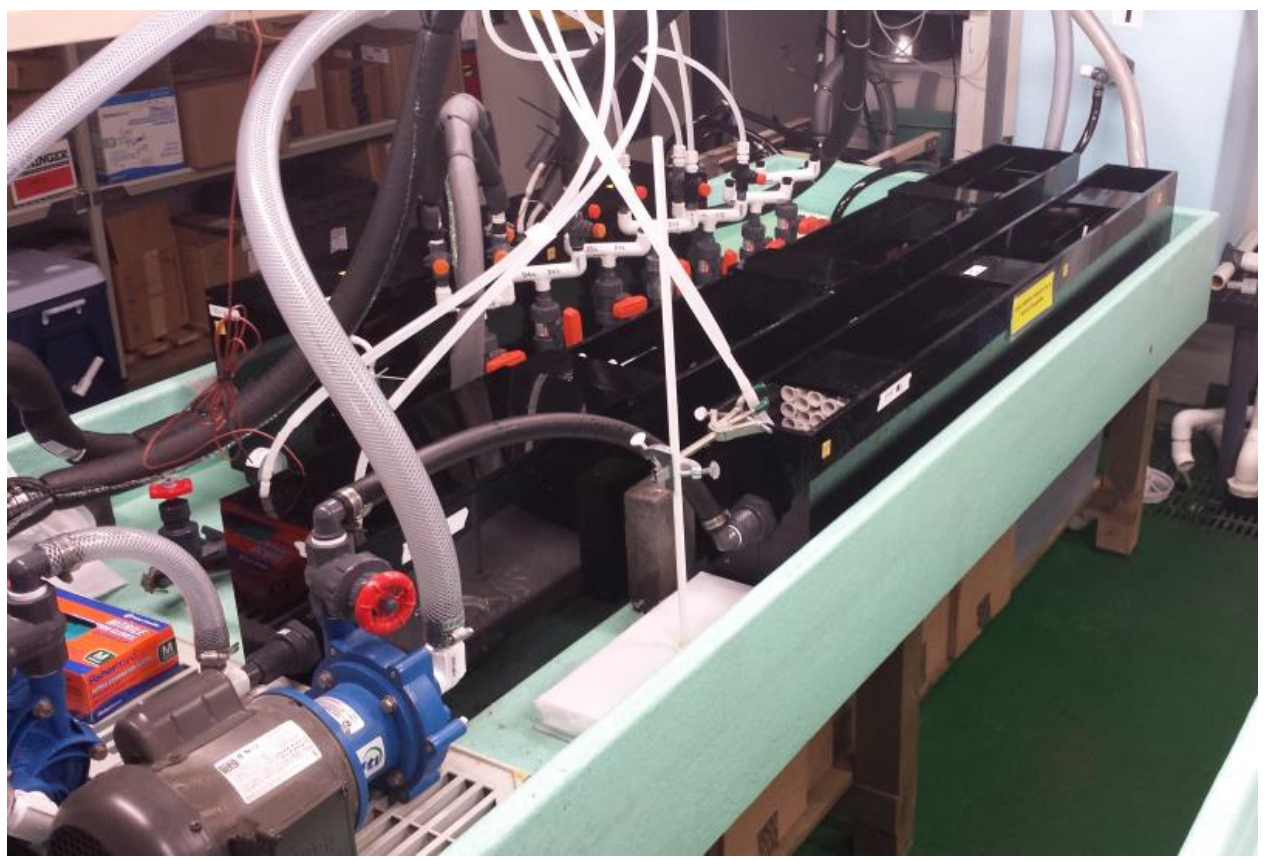

Figure 3. Flumes used for studying the effect of linear velocity on adsorption performance. The flume on the left is the $8 \mathrm{ft}$. flume (Flume B) and the flume on the right is the $6 \mathrm{ft}$. flume (Flume C) that is described in Table 2. The recirculation pump for flume $C$ is shown in the lower left side of the picture. The inlet for fresh seawater is introduced through the $1 / 2$ inch poly tubing on the near side of the flumes

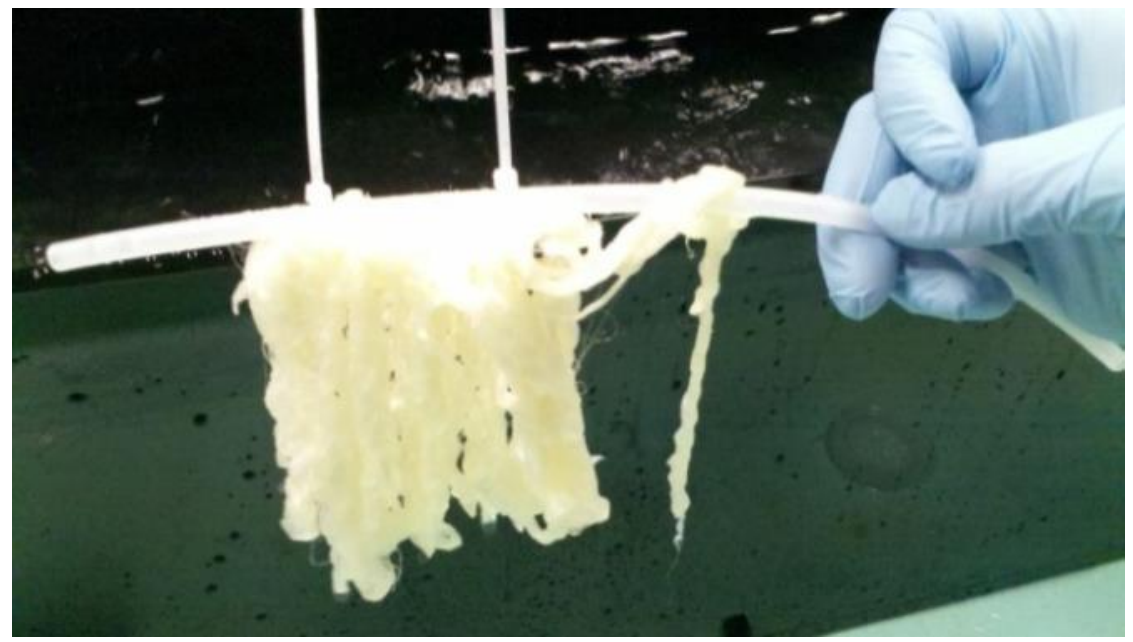

Figure 4. Adsorbent braid attached to a short length of 1/4-inch diameter polyethylene tubing. The tubing end is inserted into a PVC block attached to the bottom of the flume, fixing the braid in the flume in the desired exposure position. 


\subsection{Water Quality, Temperature and Flow-rate Monitoring}

Salinity and $\mathrm{pH}$ measurements of the seawater exposure system were obtained using handheld probes several times a week during the exposure periods. Salinity was monitored using a YSI model Pro30 and $\mathrm{pH}$ measurements were made using a portable $\mathrm{pH}$ meter (VWR Scientific) equipped with a temperature compensating glass electrode that was calibrated with National Institute of Standards and Technology (NIST) traceable buffers. The $\mathrm{pH}$ and salinity probes were calibrated weekly. High frequency (every 10 minutes) measurements of temperature in the seawater exposure systems were obtained with a thermocouple interfaced to an Omega 4 channel meter and data logger (model HH1384).

Flow-rate in the flow-through columns was monitored using an in-line turbine-style flow sensor (Model DFS-2W, Digiflow Systems) placed at the outlet of the flow-through columns. Flow-rate in the flumes was monitored using an in-line flow-meter on the recirculation line. The flow-rate in the flume was adjusted by constricting the output from the recirculation pump using a gate valve. The flow-rate was adjusted for both the columns and flume exposures to yield a linear velocity of $2 \mathrm{~cm} / \mathrm{sec}$, consistent with the flows used for seawater exposures at PNNL (Gill et al., 2016).

\subsection{Analytical Methods}

\subsubsection{Determination of Uranium and Trace Elements on Adsorbent Materials}

Analysis of uranium and other elements retained on the adsorbents was conducted at PNNL. Adsorbent materials exposed to seawater were washed with deionized water to remove salts, and the monitoring the process with a conductivity meter. Samples were then dried at $80^{\circ} \mathrm{C}$ to a constant weight using a heated block (ModBlock ${ }^{\mathrm{TM}}$, CPI International). The dried fibers (50 to $100 \mathrm{mg}$ ) were weighed and then digested with $15 \mathrm{~mL}$ of a high-purity (Trace Metal Grade, Fisher Scientific) 50\% aqua regia acid mixture (3:1; hydrochloric acid: nitric acid) for 3 hours at $85^{\circ} \mathrm{C}$ on a hot block. Analysis of uranium and other trace elements was conducted following dilution of the digestate with $20 \mathrm{~mL}$ of de-ionized water using either a Perkin-Elmer 7300 DV inductively coupled plasma optical emission spectrometer (ICP-OES) or a Thermo Scientific $\mathrm{ICap}^{\mathrm{TM}} \mathrm{Q}$ inductively coupled plasma mass spectrometer (ICP-MS). Quantification with both instruments is based on standard calibration curves.

\subsubsection{Determination of Uranium and Other Elements in Seawater}

Determination of uranium and other elements in natural seawater samples was conducted at PNNL's Marine Sciences Laboratory using ICP-MS and either the method of standard addition calibrations or the samples were pre-concentrated onto a chelating ion exchange resin to minimize the seawater matrix, followed by acid elution with quantification against a standard calibration curve prepared using on-line pre-concentration (Wood et al., 2016). On-line preconcentration of uranium was conducted using the seaFAST S2 ${ }^{\mathrm{TM}}$ automated sample 
introduction system (Elemental Scientific) utilizing a seaFAST PFA chelation column packed with iminodiacetic acid chelating ion exchange resin (ESI, Seawater Concentrator Column CF$\mathrm{N}-0200$ ). Analytes were eluted off the column using $10 \% \mathrm{HNO}_{3}$ and detected using a Thermo Elemental ICapQ ICP-MS.

\subsubsection{Fourier Transform Infrared Spectroscopy (FTIR) Analysis}

FTIR spectra were acquired using a ThermoNicolet 6700 ATR-FTIR spectrometer equipped with a DTGS detector shown in Figure 5. FTIR measurements were made with a SplitPea attenuated total reflection accessory (Harrick Scientific Corporation) along with a silicon internal reflection element used as a reflection medium. High resolution FTIR spectra in the range of 4000-700 cm-1 were acquired using 500 co-added scans at $2 \mathrm{~cm}-1$ resolution with Norton-Beer "medium" apodization function.

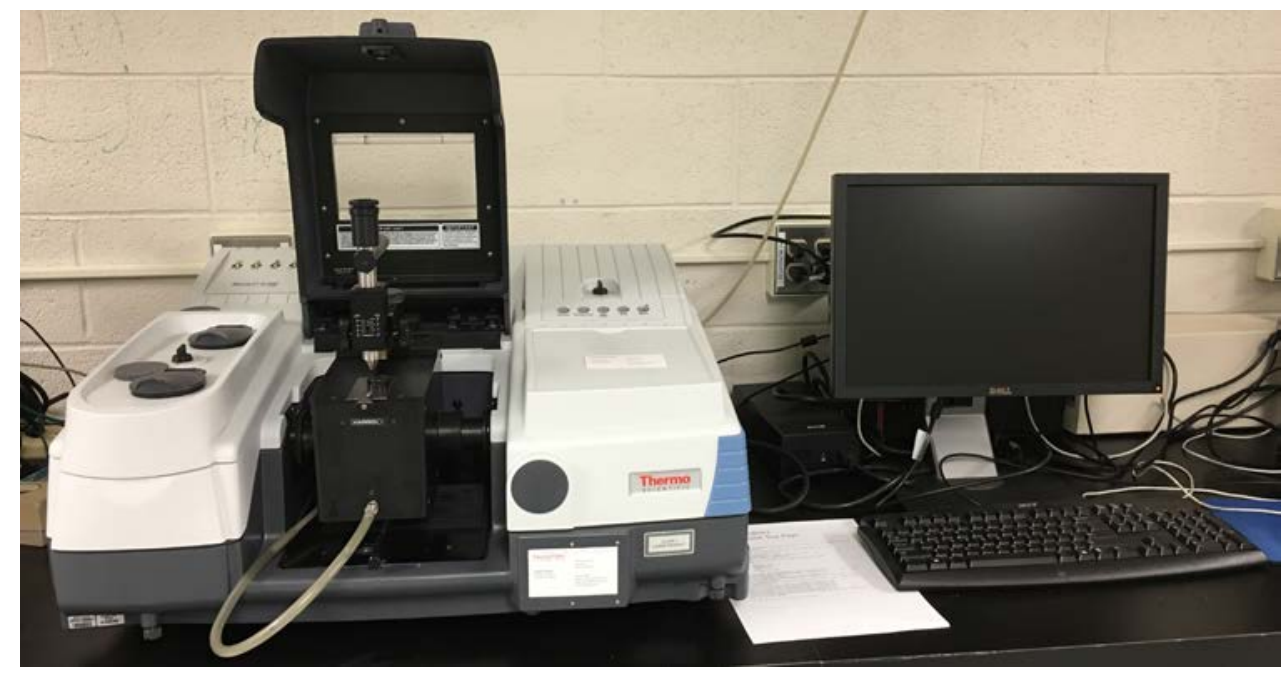

Figure 5. ThermoNicolet 6700 ATR-FTIR spectrometer

A typical FTIR spectrum of the ORNL AI8 adsorbent after conditioning with $2.5 \% \mathrm{KOH}$ solution at $80^{\circ} \mathrm{C}$ for 1 hour is shown in Figure 6. A broadband in the region of $3000-3600 \mathrm{~cm}^{-1}$ is attributed to the stretching vibrations of $-\mathrm{OH}\left(3100-3330 \mathrm{~cm}^{-1}\right)$ and $-\mathrm{NH}_{2}\left(3400-3500 \mathrm{~cm}^{-1}\right)$ groups. The two peaks observed at 2918 and $2849 \mathrm{~cm}^{-1}$ are characteristic asymmetrical stretching and symmetrical stretching vibrational bands for $-\mathrm{CH}_{2}-$, respectively. The region between $800-2000 \mathrm{~cm}^{-1}$ where absorption of various vibrational modes of amidoxime and carboxylate groups occur is of interest to this study. Three prominent peaks of interest in this region are the $928 \mathrm{~cm}^{-1}$ band $\left(\mathrm{N}-\mathrm{O}\right.$ stretcing), the $1559 \mathrm{~cm}^{-1}$ band $\left(-\mathrm{COO}^{-}\right.$asymmetrical stretching), and the $1643 \mathrm{~cm}^{-1}$ band ( $\mathrm{C}=\mathrm{N}$ stretching). The peaks in each sample are normalized to the $-\mathrm{CH}_{2}-$ asymmetrical stretching band at $2918 \mathrm{~cm}^{-1}$ which is not affected by the $\mathrm{KOH}$ conditioning and elution method. 


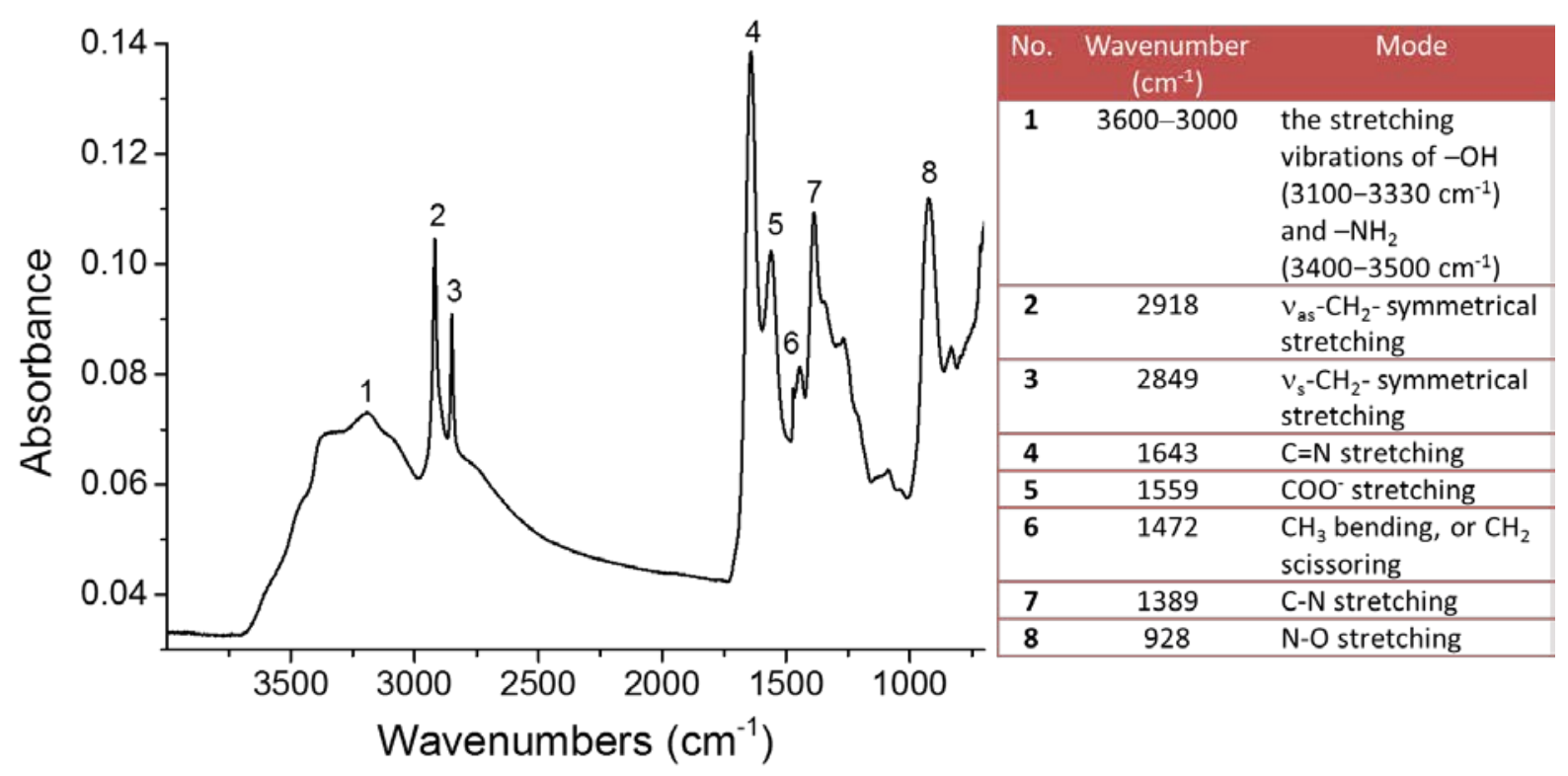

Figure 6. FTIR spectrum of the AF1L2R3 sorbent after conditioning with $2.5 \% \mathrm{KOH}$ solution at $80{ }^{\circ} \mathrm{C}$ for 1 hour

\subsection{One-Site Ligand Saturation Modeling}

Measurements of the adsorption of uranium and other elements from seawater as a function of time onto the adsorbent materials were used to determine the adsorbent capacity and adsorption rate (kinetics) of uranium and other elements. Determination of adsorption capacity and kinetics was conducted using one-site ligand saturation modeling, which was parameterized using the software graphics program SigmaPlot $@$. The best-fit line representing the time series adsorption of uranium is given by:

$$
u=\frac{\beta_{\max } t}{K_{d}+t}
$$

Where $\mathrm{u}$ is uranium capacity ( $\mathrm{g} \mathrm{U} / \mathrm{kg}$ adsorbent), $\mathrm{t}$ is exposure time (days), $\beta_{\max }$ is the adsorption capacity at saturation (g U/kg adsorbent), and $\mathrm{K}_{\mathrm{d}}$ is the half-saturation time (days).

Prior to determination of adsorption capacity and kinetics, the individual capacity determinations were normalized to a salinity of 35 psu using simple proportional relationships. This normalization removes the differences that result from exposures in seawater with varying salinity and hence uranium concentrations. This salinity normalization is also done for the other elements as well, but the normalization is less well defined for non-conservative elements in seawater. 
PNNL-25874

\subsection{Recycling Approaches for Re-use of Amidoxime-Based Uranium Adsorbents}

For uranium adsorbents to be repeatedly used, it is important to have recycling approach that can effectively strip off uranium from the adsorbents without causing a significant performance impact on uranium adsorption capacity. A typical approach to recover uranium adsorbents is acid elution (e.g. HCl) (Suzuki et al., 2000; Seko et al., 2005; Pan et al., 2014). However, it is also known that acid elution $(0.5 \mathrm{M} \mathrm{HCl})$ can deteriorate the adsorbent due to acid hydrolysis of amidoxime groups (Pan et al., 2014). Alternative mild uranium stripping approaches were thus developed for uranium adsorbent re-use (Pan et al., 2014; Pan et al., 2015). However, natural organic matter (NOM) adsorbed on the surface of the adsorbent could affect the rate of uranium adsorption/desorption and thus affect the reuse of adsorbent in real seawater experiments. The NOM effect is not observed in the simulated seawater experiment. Therefore, in the present study, we developed and evaluated the effectiveness of a sequential potassium bicarbonate and $\mathrm{NaOH}$ elution method. A detailed description of the sequential bicarbonate and $\mathrm{NaOH}$ elution approach follows.

\subsubsection{Recycling Approach: Bicarbonate - NaOH Coupled Elution}

In real seawater experiments, the adsorption of natural organic matter (NOM) can affect the uranium adsorption capacity of the recycled adsorbent. After weeks of real seawater exposure, the adsorbents exhibited a dark brown color (adsorbed NOM) which was not observed in the simulated seawater experiment. Neither bicarbonate elution nor $\mathrm{HCl}$ leaching removed the dark color. However, using an alkaline solution soaking under room temperature, the braid changed color from dark brown to light brown. Since NOM such as humic substances can be dissolved in alkaline solutions, this observation provides preliminary evidence of NOM adsorption by amidoxime-based polymeric adsorbents during exposure in real seawater. The seawater-exposed adsorbent was treated first by the bicarbonate elution method ( $3 \mathrm{M} \mathrm{KHCO}_{3}$ at $40^{\circ} \mathrm{C}$ for 24 hours) to strip off uranium followed by a $\mathrm{NaOH}$ soaking $(0.5 \mathrm{M}$, at room temperature for 3 hours) to remove $\mathrm{NOM}$ from the adsorbent. Without the $\mathrm{NaOH}$ treatment, the recycled adsorbent with only $\mathrm{KHCO}_{3}$ elution showed about $45 \%$ reduction in uranium adsorption capacity in the seawater exposure experiment.

\subsection{Preparation of Amidoxime-based Polymeric Adsorbent Braids}

Several formulations (AI8, AF8, AF1, AF1-DMSO) of amidoxime-based, high-surface area polyethylene fibrous braids were prepared by Chris Janke, Richard Mayes, and Sadananda Das at Oak Ridge National Laboratory (ORNL) using the radiation-induced graft polymerization (RIGP) method (Kim et al., 2013, 2014; Janke et al., 2013; Das et al., 2016a; Das et al., 2016b; Das et al., 2016c). The RIGP method involves four processing steps: (1) electron beam irradiation of high surface area polyethylene fibers, (2) co-grafting polymerizable monomers containing nitrile groups and hydrophilic groups to form grafted side chains throughout the fiber, 
(3) conversion of nitrile groups to amidoxime groups, and (4) alkaline conditioning of the grafted fibers. Grafted braid materials were shipped dry to PNNL and they were conditioned immediately before the seawater exposure. The conditioning procedure consisted of gently stirring the fibers in a $2.5 \%(\sim 0.44 \mathrm{M})$ potassium hydroxide $(\mathrm{KOH})$ solution at $80^{\circ} \mathrm{C}$ for 1 hour. One $\mathrm{mL}$ of $\mathrm{KOH}$ solution was used per mg of adsorbent material. Due to the large size of braid material (up to $7 \mathrm{~g}$ ), conditioning was conducted in a carboy and heated using an incubated shaker (Thermo Scientific MaxQ ${ }^{\mathrm{TM}}$ 6000). Immediately after conditioning, the braids were rinsed several times with deionized water until neutral $\mathrm{pH}$ was reached. The conditioned braids were stored in a pre-cleaned HDPE bottle filled with deionized water until placed in the flume for natural seawater exposure.

\subsection{Multi-cycle Adsorbent Re-use Test}

A multi-cycle adsorbent re-use test was conducted using several different formulations of the amidoxime-based polymer adsorbents provided by ORNL (described above). Exposures were conducted with natural filtered seawater using the PNNL flume system described previously. The seawater exposure cycle for ORNL braids were either 28- or 42-day in duration. The procedure includes an initial seawater exposure, a sequential $\mathrm{KHCO}_{3}$ and $\mathrm{NaOH}$ elution to remove uranium and other trace elements, and then re-deployment to the flume to start the next re-use cycle. During the seawater exposure, a "snip" of approximately $100 \mathrm{mg}$ of adsorbent fiber was taken from each braid at different time points using a pair of titanium coated scissors. These time series subsamples provide the sorption kinetics information of uranium and other trace elements. Furthermore, we sampled some adsorbent fibers in every major adsorbent treatment step, including before and after $\mathrm{KOH}$ conditioning, after each cycle of seawater exposure, and after each chemical treatment.

\subsubsection{Flume Operation}

The $122 \mathrm{~cm}$ (4 ft.) length by $20.3 \mathrm{~cm}$ (8 inches) width opaque flume was used in this study. The water depth in the flume was held at $22.9 \mathrm{~cm}$ (9 inches) making the total volume in the flume $57 \mathrm{~L}$. The flow rate of fresh filtered $(0.45 \mu \mathrm{m})$ seawater was introduced at $\geq 3 \mathrm{~L} / \mathrm{min}$. The seawater recirculation pump was adjusted to $50 \mathrm{~L} / \mathrm{min}$ (LPM). The combination of the introduction of fresh seawater and recirculated seawater produced a linear velocity of 2.0 $\mathrm{cm} /$ second. Seawater temperature was controlled at $20^{\circ} \mathrm{C}$.

\subsubsection{Characterization of Adsorbents}

All samples were characterized with Fourier Transform Infrared Spectroscopy (FTIR) and trace element analysis. These determinations provide valuable information on potential alterations of surface functional groups during different treatments and repeated seawater deployment. 


\subsection{Results and Discussion}

\subsection{Improvement of Adsorbent Reusability by Organic Matter Removal}

As shown in the preliminary test (Figure 1), treatment of the seawater-exposed adsorbent with an alkaline solution such as $\mathrm{NaOH}$ improves the uranium adsorption capacity upon re-use. We conducted a follow-up to examine OM adsorption and removal from seawater exposed braids using a $\mathrm{NaOH}$ rinse. Three seawater-exposed ORNL braids, including one AI8 braid and two AF1 braids, were rinsed for three hours with $0.5 \mathrm{M} \mathrm{NaOH}$ after being stripping of uranium using $3 \mathrm{M} \mathrm{KHCO}_{3}$ elution. The $\mathrm{NaOH}$ solutions were analyzed for DOC analysis using a total organic carbon analyzer (Shimadzu TOC-LCSH). Table 2 lists the OC content removed from the braids in the $\mathrm{NaOH}$ rinse. Substantially more OC was removed from the 42-day seawater exposed AF1 braid (>50\%) than the two 28-day seawater exposed braids, which have similar OC removal although they are different adsorbent types (AF1 and AI8). The difference in OC removal between 28-d and 42-d braids suggests that longer exposure times leads to increased $\mathrm{OM}$ adsorption. The test also demonstrates that $0.5 \mathrm{M} \mathrm{NaOH}$ rinsing can be used to remove adsorbed OM from the adsorbents, but it is unclear how efficient the alkaline rinsing is at removing all the adsorbed OM.

Table 2. Estimated dissolved organic carbon (DOC) content removed from three separate seawaterexposed ORNL braids by $\mathrm{NaOH}$ rinsing.

\begin{tabular}{cccc}
\hline Braid & $\begin{array}{c}\text { Exposure Time } \\
\text { per Cycle } \\
\text { (d) }\end{array}$ & Re-use Cycle & $\begin{array}{c}\text { Estimated DOC Content } \\
\text { Removed from Braid } \\
\text { (mg/g) }\end{array}$ \\
\hline ORNL AI8 & 28 & 2 & 0.41 \\
ORNL AF1 & 28 & 2 & 0.37 \\
ORNL AF1 & 42 & 1 & 0.63 \\
\hline
\end{tabular}

Figure 7 shows a comparison of uranium adsorption kinetics before and after re-use with the adsorbent recycling procedure $\left(\mathrm{KHCO}_{3}\right.$ elution $+\mathrm{NaOH}$ rinse). Two individual ORNL AI8 braids were used, one braid underwent a 28-day seawater exposure cycle and the other was in a 42-day seawater exposure cycle. Both braids demonstrated excellent recovery of uranium adsorption capacity upon re-use. The recoveries of uranium capacity were $102 \pm 1 \%$ and $97 \pm$ 3\%, for the 28-day and 42-day exposures, respectively. 
PNNL-25874

(a)

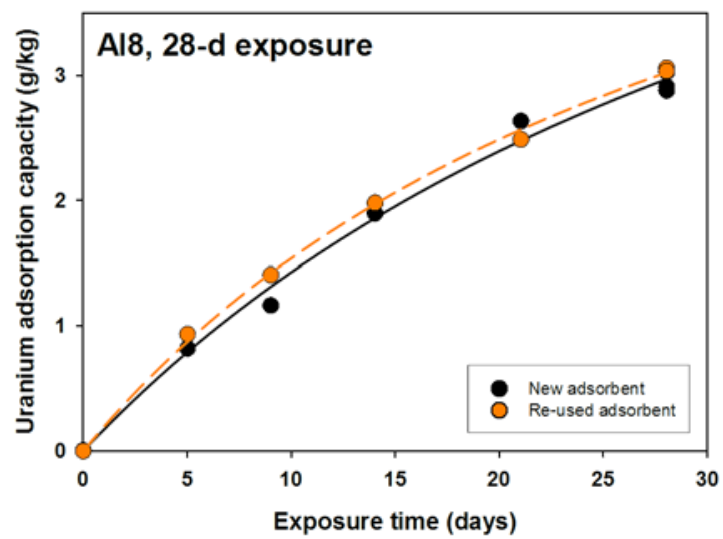

(b)

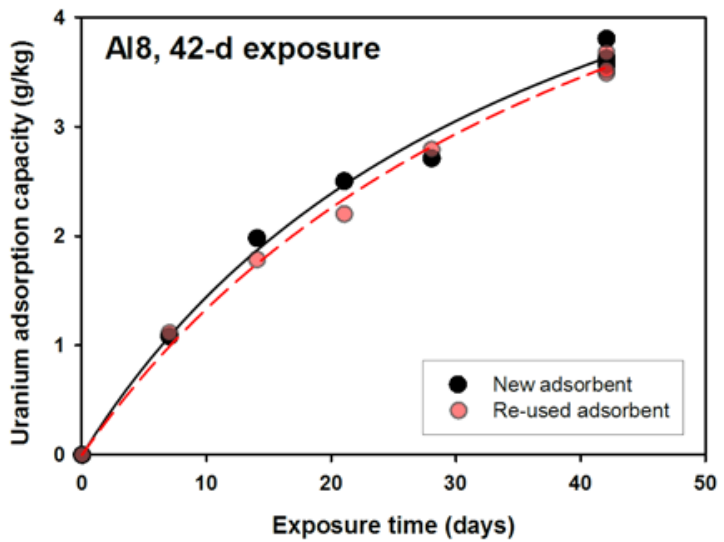

Figure 7. Comparison of uranium adsorption kinetics of two ORNL AI8 braids during initial seawater exposure and re-exposure after $\mathrm{KHCO}_{3}+\mathrm{NaOH}$ treatment: (a) an ORNL AI8 braid tested in 28-day seawater exposure cycle; (b) an ORNL AI8 braid tested in 42-day seawater exposure cycle.

Snips were taken from braids after each treatment step for FT-IR analysis to further evaluate the effects of $\mathrm{KHCO}_{3}$ elution followed by a $\mathrm{NaOH}$ rinse on the surface chemistry of the adsorbents. FT-IR spectra of the ORNL AI8 adsorbents at four different stages in the load/recycle process (before seawater exposure, after 28 days seawater exposure, after $\mathrm{KHCO}_{3}$ elution, and finally after a $\mathrm{NaOH}$ rinse) are shown in Figure 8. Quantitative results of two signatures related to amidoxime ligand (intensity of the $928 \mathrm{~cm}^{-1}$ peak $(\mathrm{N}-\mathrm{O}$ stretching) and the relative ratio of the $1643 \mathrm{~cm}^{-1} / 1559 \mathrm{~cm}^{-1}$ peaks $\left(\mathrm{C}=\mathrm{N} /-\mathrm{COO}^{-}\right.$stretching) $)$of the four stages were listed in Table 3. After the braid was in contact with seawater for 28 days, the $928 \mathrm{~cm}^{-1}$ peak decreased $12 \%$, suggesting the degradation of amidoxime ligands. However, both $\mathrm{KHCO}_{3}$ elution and $\mathrm{NaOH}$ rinse did not further alter the $928 \mathrm{~cm}^{-1}$ peak intensity. A significant decrease after seawater exposure, but not after $\mathrm{KHCO}_{3}$ and $\mathrm{NaOH}$ treatments, was also observed in the $1643 \mathrm{~cm}^{-1} / 1559 \mathrm{~cm}^{-1}$ peak ratio. The decrease in ratio of the $1643 \mathrm{~cm}^{-1} / 1559 \mathrm{~cm}^{-1}$ peaks is a combined result of decrease of $\mathrm{C}=\mathrm{N}$ and increase of the $-\mathrm{COO}^{-}$peak. These results demonstrate that both $\mathrm{KHCO}_{3}$ and $\mathrm{NaOH}$ treatments are very mild and do not damage the amidoxime ligands. This stands in marked contrast to acid leaching where significant degredaton can occur (Pan et al., 2016). Moreover, this FTIR spectra evidence supports our hypothesis that amidoxime ligands are converted to carboxylate ligands during seawater exposure. 
PNNL-25874

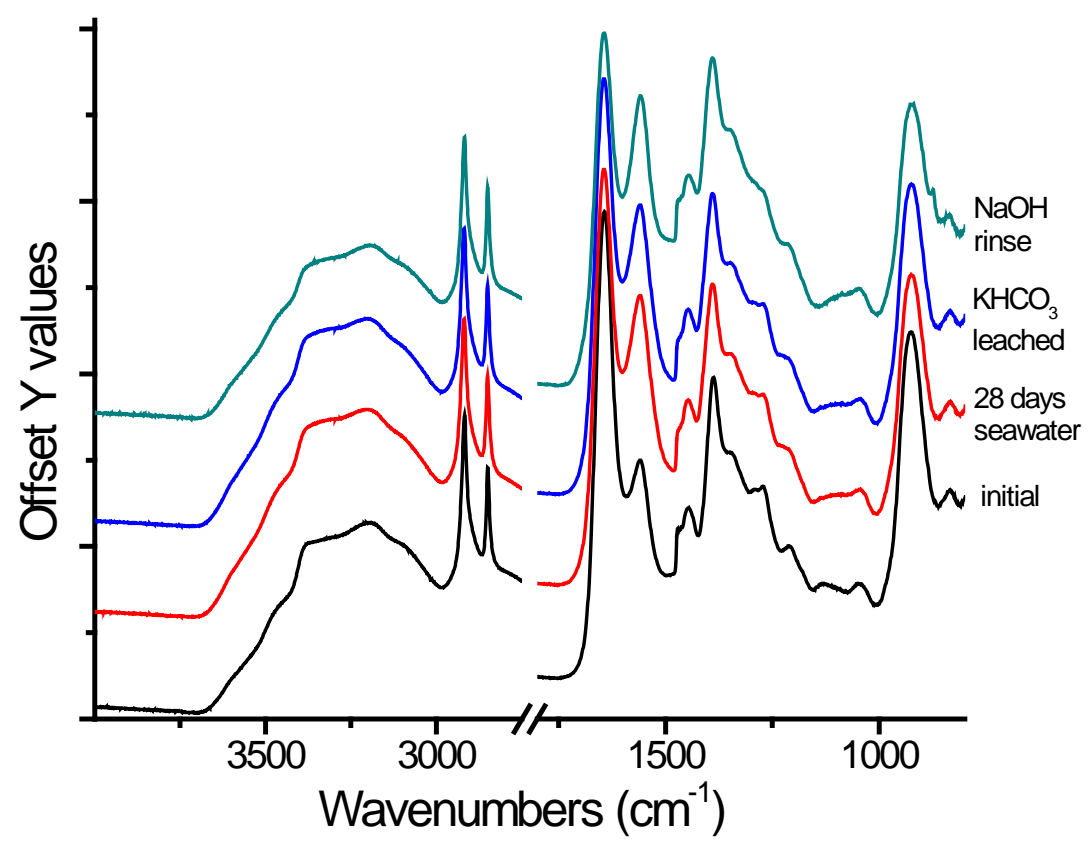

Figure 8. Comparison of FT-IR spectra of an ORNL AI8 adsorbent in sequential treatments: before seawater exposure, after 28-day seawater exposure, after $\mathrm{KHCO}_{3}$ elution, and after the $\mathrm{NaOH}$ rinse, respectively.

Table 3 FT-IR signatures (ratio of $\mathrm{I}_{1643} \mathrm{I}_{1559}$, peak intensity of $\mathrm{I}_{928}$ ) of an ORNL AI8 adsorbent under sequential treatments. The FT-IR spectra were shown in Figure 10.

\begin{tabular}{ccc}
\hline IR peak ratio & \\
ORNL Al8 braid & $I_{1643} /_{1559}$ & IR peak intensity $I_{928}$ \\
\hline Initial & 1.641 & 0.618 \\
After 28 days seawater & 1.286 & 0.546 \\
exposure & 1.288 & 0.548 \\
After $\mathrm{KHCO}_{3}$ elution & 1.257 & 0.528 \\
After NaOH rinse &
\end{tabular}

\subsection{Adsorbent Reusability Performance After Multi-Reuse Cycles}

\subsubsection{Reusability of the ORNL Adsorbent Formulation Al8}

The performance of uranium adsorbents after multiple load/stripping cycles was evaluated. An ORNL AI8 braid was re-used four times (five total exposures) with $\mathrm{KHCO}_{3}$ elution followed by $\mathrm{NaOH}$ rinse after each seawater exposure. After the first re-use (or third deployment), the uranium adsorption capacity decreased significantly with re-use (Figure 9). The 56-day uranium adsorption capacity, saturation capacity, and half-saturation time for the different re-use cycles is given in Table 4 . The uranium adsorption capacity dropped substantially beginning with the $2^{\text {nd }}$ re-use ( ${ }^{\text {rd }}$ exposure). Relative to the capacity of the initial exposure, upon re-use the 56-day adsorption capacity dropped to $97 \%, 70 \%, 46 \%, 28 \%$ in the $1^{\text {st }}, 2^{\text {nd }}, 3^{\text {rd }}$, and $4^{\text {th }}$ re-uses, 
respectively. Concomitantly, both the saturation capacity and half-saturation time also decreased with the number of re-uses. We hypothesize that the drop in performance with re-use is caused by conversion of the grafted amidoxime to carboxylate during seawater exposure, not by the slower adsorption rate.

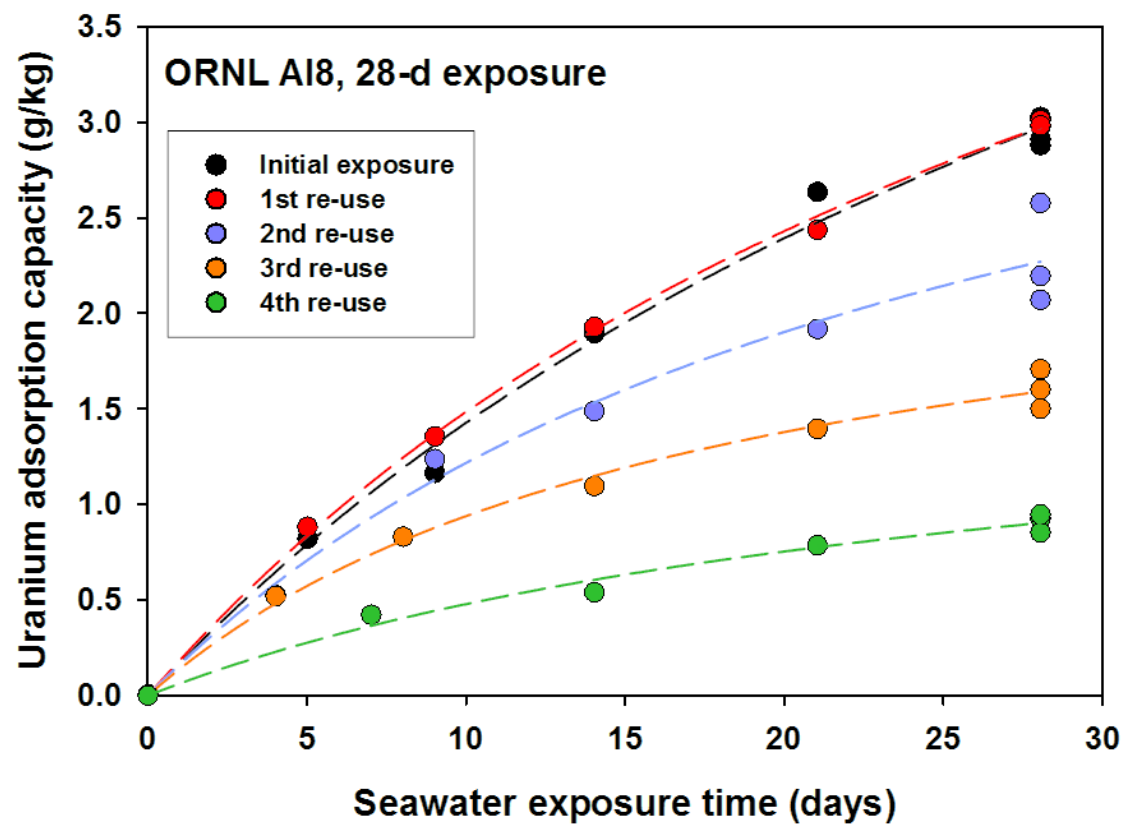

Figure 9. Uranium adsorption kinetics of an ORNL AI8 braid that was subjected to five, 28-day exposure, adsorption/stripping cycles. All data were normalized to a salinity of 35. The kinetics data were modeled using one-site ligand saturation modeling.

Table 4 One-site ligand saturation modeling of time-dependent measurements of an ORNL AI8 braid subjected to five, 28-day exposure, adsorption/stripping cycles. All data were normalized to a salinity of 35.

\begin{tabular}{cccc}
\hline $\begin{array}{c}\text { ORNL AI8 Re- } \\
\text { use Cycle }\end{array}$ & $\begin{array}{c}\text { 56-day } \\
\text { Adsorption } \\
\text { Capacity (g/kg) }\end{array}$ & $\begin{array}{c}\text { Saturation Capacity } \\
\mathbf{( g / k g )}\end{array}$ & $\begin{array}{c}\text { Half-saturation time } \\
\text { (days) }\end{array}$ \\
\hline Initial & $4.24 \pm 0.97$ & $7.41 \pm 1.14$ & $41.8 \pm 10.0$ \\
$1^{\text {st }}$ re-use & $4.12 \pm 0.31$ & $6.70 \pm 0.33$ & $35.0 \pm 2.87$ \\
$2^{\text {nd }}$ re-use & $2.99 \pm 0.78$ & $4.37 \pm 0.92$ & $25.8 \pm 10.2$ \\
$3^{\text {rd }}$ re-use & $1.97 \pm 0.22$ & $2.59 \pm 0.23$ & $17.5 \pm 3.5$ \\
$4^{\text {th }}$ re-use & $1.19 \pm 0.29$ & $1.77 \pm 0.34$ & $27.0 \pm 9.6$ \\
\hline
\end{tabular}

To investigate the cause of poor uranium adsorption capacity after multiple re-uses, braid snips collected at different time points during the course of re-use experiment were analyzed by FT-IR (Figure 10). The FT-IR spectra clearly show that the $928 \mathrm{~cm}^{-1}$ peak $(\mathrm{N}-\mathrm{O}$ stretching) and 
the $1643 \mathrm{~cm}^{-1}$ peak ( $\mathrm{C}=\mathrm{N}$ stretching) became smaller over time; while the $1559 \mathrm{~cm}^{-1}$ peak ($\mathrm{COO}^{-}$stretching) increased. The decreases of peak intensities of $\mathrm{N}-\mathrm{O}$ stretching and $\mathrm{C}=\mathrm{N}$ stretching suggest the degradation of amidoxime ligands. The concurrent increase of peak intensity of $-\mathrm{COO}^{-}$stretching suggests the formation of $-\mathrm{COO}^{-}$from degradation of amidoxime ligands during seawater exposure (Pan et al., 2015; Pan et al., 2016a). The potential degradation of amidoxime ligands to carboxylate group during seawater exposure is further supported by comparing the ratios of $\mathrm{Ca}$ vs. $\mathrm{U}$ and $\mathrm{Mg}$ vs. $\mathrm{U}$ (Figure 11). Both $\mathrm{Ca}^{2+}$ and $\mathrm{Mg}^{2+}$ are the major doubly-charged cations in seawater and their binding on the ORNL polymeric adsorbents is primarily on carboxylate group, not amidoxime ligands (Kuo et al., 2016). Thus, ratios of $\mathrm{Ca} / \mathrm{U}$ and $\mathrm{Mg} / \mathrm{U}$ can be usful indices of degradation of amidoxime-based adsorbents. The significant increases of the two ratios in Figure 11 point to the degradation of the tested ORNL AI8 braid and are consistent with the observations on both uranium adsorption performance and FT-IR spectra.

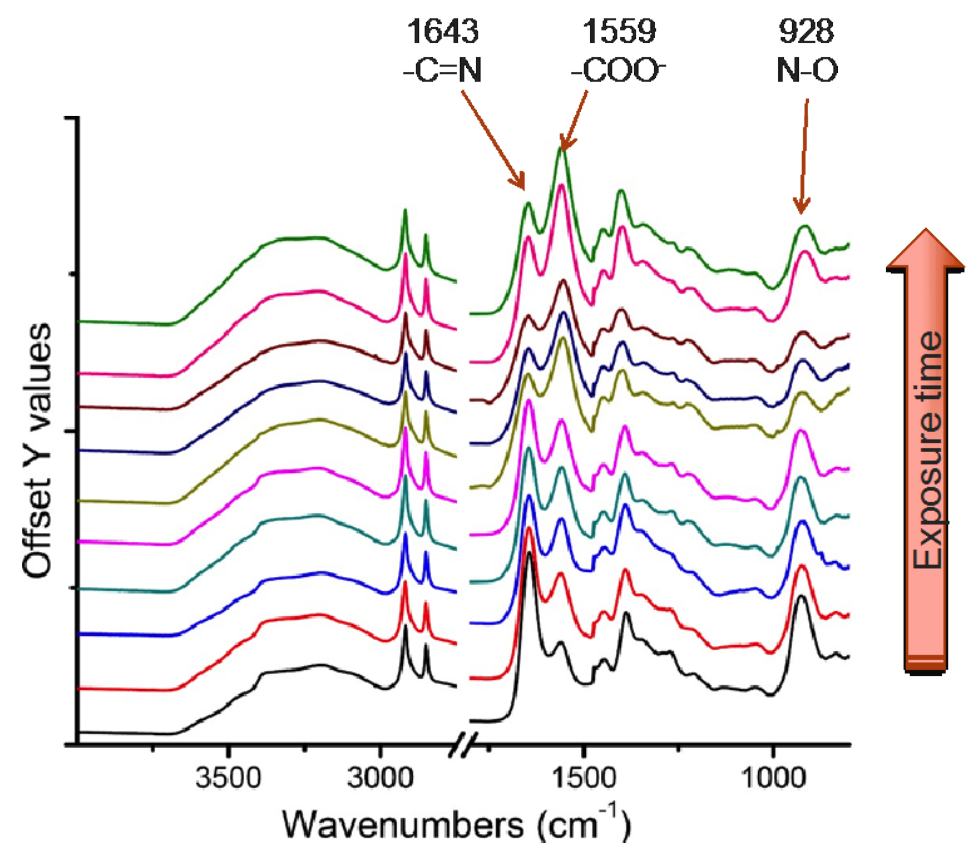

Figure 10. Comparison of FT-IR spectra of an ORNL AI8 braid underwent a 28-day initial seawater exposure followed by re-exposures after the $\mathrm{KHCO}_{3}+\mathrm{NaOH}$ elution. The Each spectrum was from a braid snip sampled at a specific time point during the course of seawater exposure. The spectra were stacked from bottom to top with increasing seawater exposure time. 
PNNL-25874

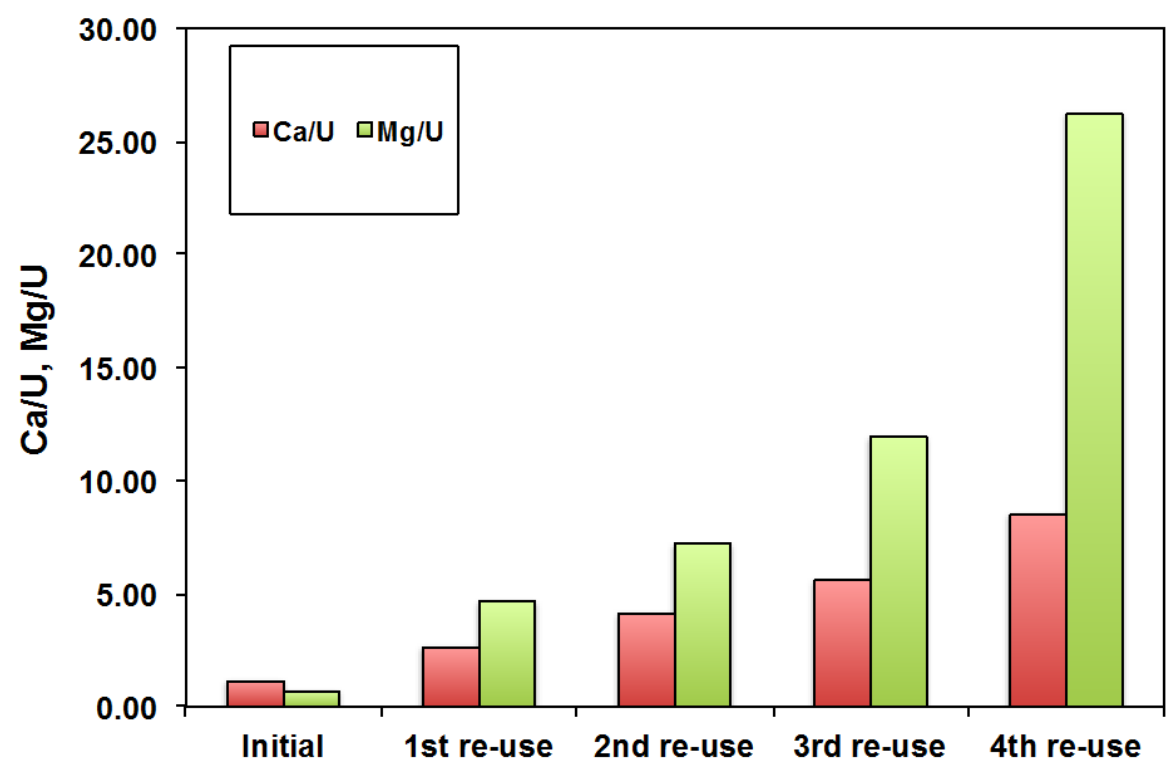

Figure 11. Changes of ratios of $\mathrm{Ca}, \mathrm{Mg}$ vs. $U$ from braid snips collected in the end of each seawater exposure during the recycling study of an ORNL AI8 braid. Each cycle of the seawater exposure is 28 days. Before each seawater re-exposure, the braid was treated with $\mathrm{KHCO}_{3}+\mathrm{NaOH}$ elution to remove uranium and other elements, including Ca and $\mathrm{Mg}$.

\subsubsection{Reusability of the ORNL Adsorbent Formulation AF1}

The reusability tests conducted for the AI8 formulation were repeated using the ORNL amidoxime-based braid formulation AF1. For these experiments, the recycle period was lengthened to a 56-day exposure and the time course sampling frequency was increased to provide more detail. As shown in Figure 12, along the course of seawater exposure, the peak intensity of $928 \mathrm{~cm}^{-1}\left(\mathrm{~N}-\mathrm{O}\right.$ stretching) and the $1643 \mathrm{~cm}^{-1}(\mathrm{C}=\mathrm{N}$ stretching) decreased over time; while that of the $1559 \mathrm{~cm}^{-1}$ (-COO${ }^{-}$stretching) continuously increased and eventually was higher than the intensity of $1643 \mathrm{~cm}^{-1}$ peak. Using peak intensity of the $928 \mathrm{~cm}^{-1}$ peak $(\mathrm{N}-\mathrm{O}$ stretching) as a proxy of amidoxime ligands (Figure 13), the amidoxime ligands decreased substantially even during the initial 56-day seawater exposure ( 35\% decrease in $928 \mathrm{~cm}^{-1}$ peak intensity) and further decreased during seawater re-exposure in the first re-use ( $65 \%$ decrease at the end of the first re-use). Evidence of an increase of carboxylate groups from degradation of amidoxime ligands is supported by ratios of $\mathrm{Ca} / \mathrm{U}$ and $\mathrm{Mg} / \mathrm{U}$ (Figure 14), which show marked increases from the initial seawater exposure to the $1^{\text {st }}$ and $2^{\text {nd }}$ re-uses. The significant temporal changes of surface functionality of the adsorbent during seawater exposure (Figure 12) and the insignificant change of FT-IR signatures following $\mathrm{KHCO}_{3}$ elution and $\mathrm{NaOH}$ rinse (Figure 8) indicate that degradation of amidoxime ligands happened during the seawater exposure, not as a result of the uranium stripping processes. While the degradation of the amidoxime ligand from seawater exposure is clear, the mechanism(s) (e.g. biological or chemcial) are still unknown. 
Initial 56-d exposure

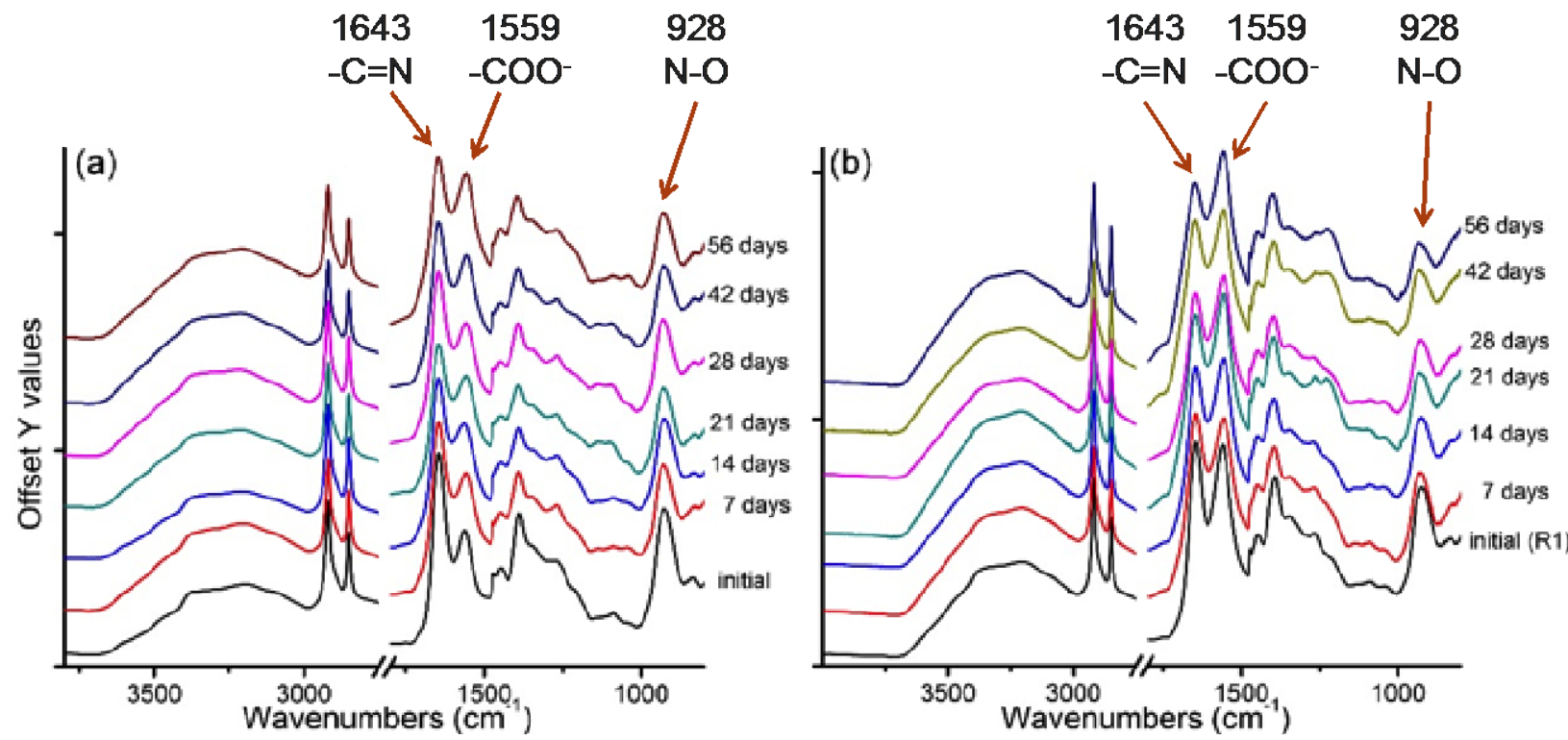

Figure 12. Time course FT-IR spectra of an ORNL AF1 braid after a 56-day initial seawater exposure (left panel) followed by re-exposure to seawater after the $\mathrm{KHCO}_{3}+\mathrm{NaOH}$ elution steps (right panel). Each spectrum was from a braid snip sampled at a specific time point during the course of the seawater exposures.

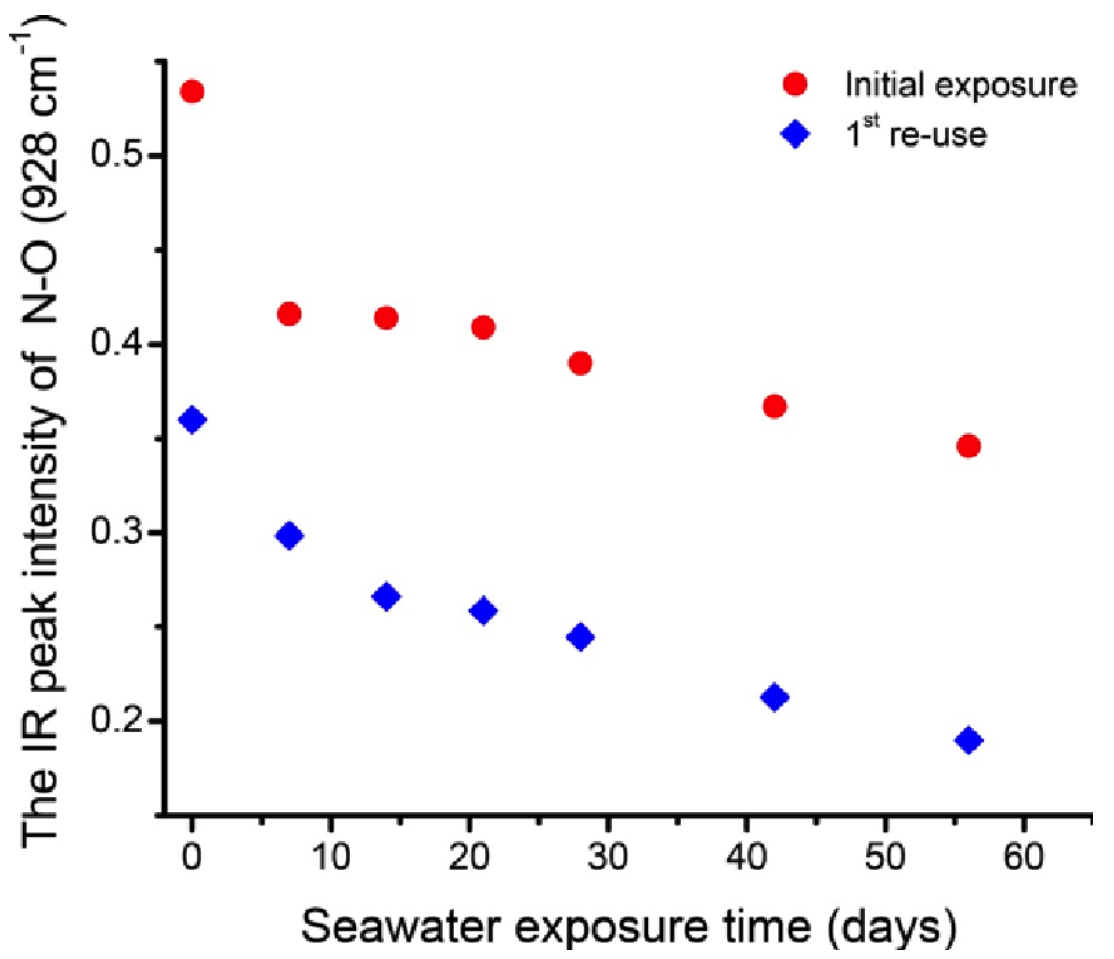

Figure 13. Time course changes in the FT-IR intensity of the $928 \mathrm{~cm}^{-1}(\mathrm{~N}-\mathrm{O}$ stretching) peak obtained during a 56-day exposure of the ORNL AF1 braid. Before seawater re-exposure, the braid was treated with $\mathrm{KHCO}_{3}+\mathrm{NaOH}$ elution to remove uranium and adsorbed natural organic matter. 
PNNL-25874

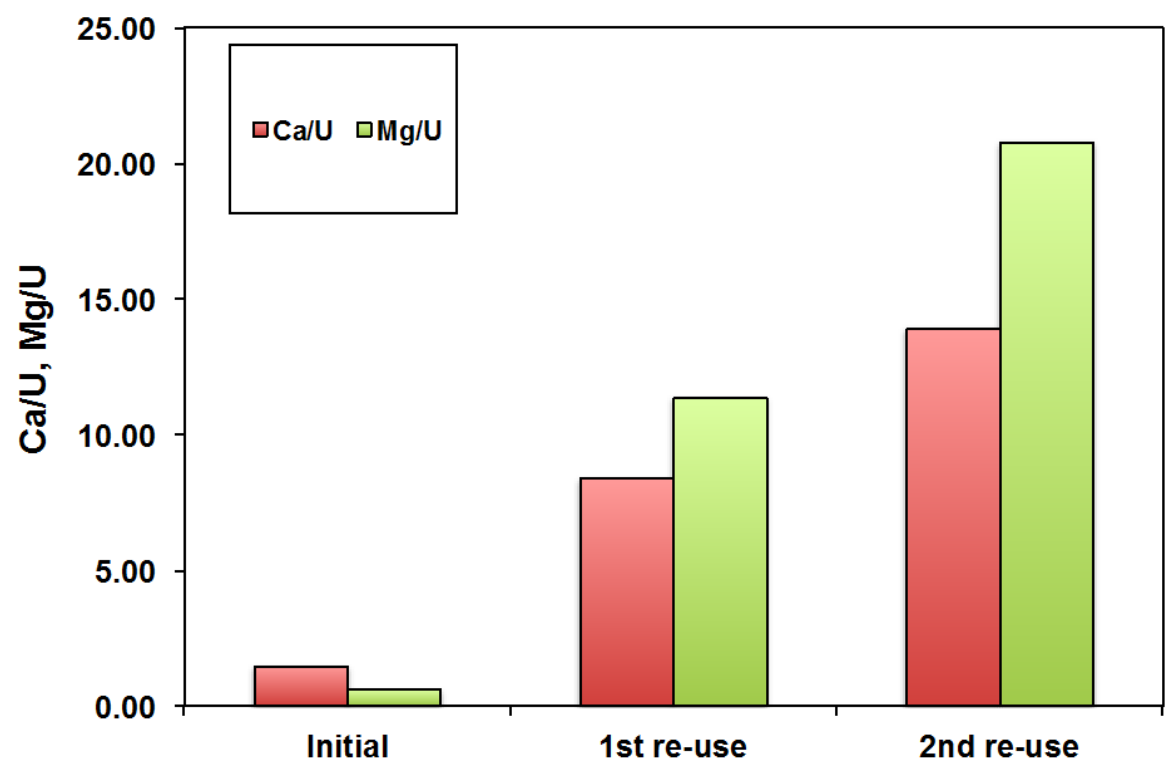

Figure 14. Changes of ratios of $\mathrm{Ca}, \mathrm{Mg}$ vs. $\mathrm{U}$ from braid snips collected in the end of each seawater exposure during a recycling study with an ORNL AF1 braid. Each cycle of the seawater exposure is 56 days. Before each seawater re-exposure, the braid was treated with $\mathrm{KHCO}_{3}+\mathrm{NaOH}$ elution to remove uranium and other elements, including Ca and Mg.

\subsection{Effects of seawater exposure time and adsorbent types on adsorbent reusability}

The observed degradation of amidoxime-based polymeric adsorbents during seawater exposure (Figures 10-14) suggests that total seawater exposure time is a critical parameter limiting the reusability of adsorbents. More natural organic matter adsorption on uranium adsorbents also will occur during prolonged seawater exposure, as demonstrated in Table 2. In addition, exposure in unfiltered seawater will result in a loss of adsorption capacity due to biofouling, which also varies with exposure time (Park et al., 2016). Collectively, these observations permit us to hypothesize that the longer the seawater exposure time, between each recycling event, the greater the overall performance drop will be for adsorbent re-use.

To test this hypothesis, two ORNL AI8 braids were exposed in the same flume but with different seawater exposure times. One braid was on 28-day cycle and the other was on 42-day cycle. After each seawater exposure cycle, the braids were stripped of uranium and adsorbed organic matter using $\mathrm{KHCO}_{3}$ elution followed by a $\mathrm{NaOH}$ rinse. The braids were re-deployed to start a new cycle of seawater exposure (re-use). The braid with 28 days seawater exposure cycle was re-used four times; while the braid with 42 days seawater exposure cycle was re-used three times. This resulted in a total deployment time of 140 days for the 28-day cycle exposure and 168 days for the 42-day cycle exposure. The results of this experiment are depicted in Figure 15. 


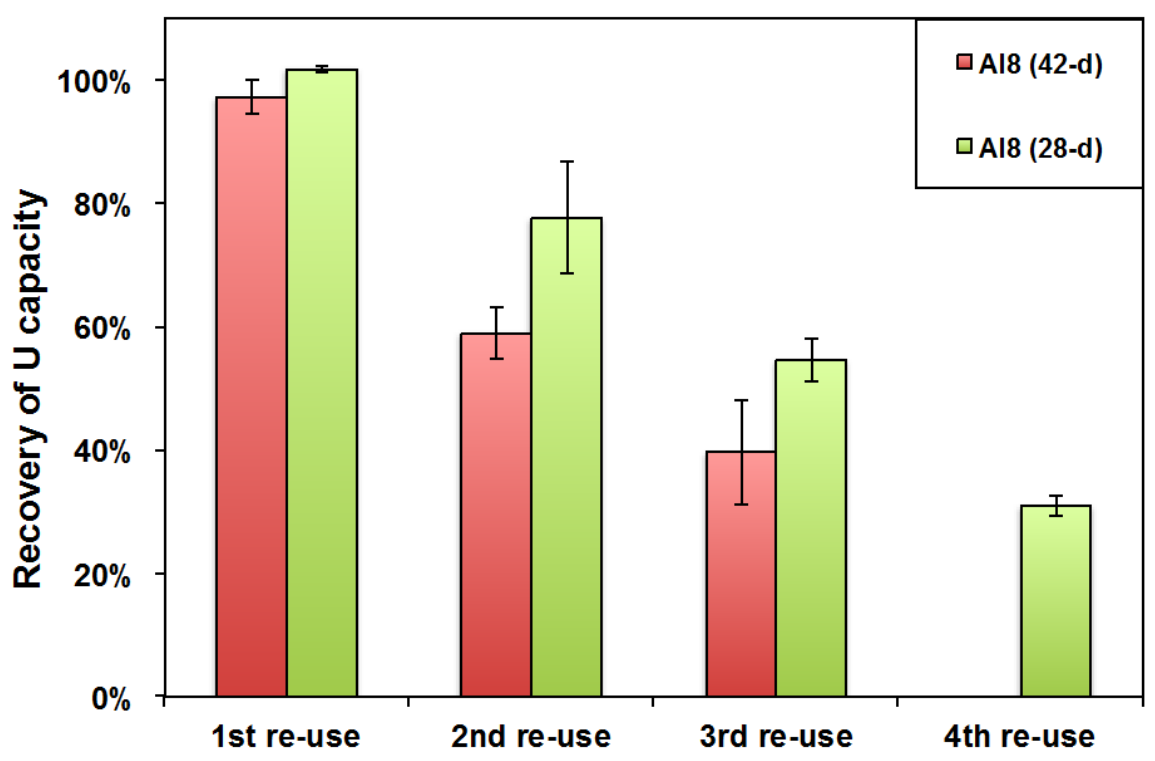

Figure 15. Recovery of uranium adsorption capacity of two ORNL AI8 braids in re-uses. One braid was on 28 days seawater exposure cycle (four re-uses were conducted); another was on 42 days seawater exposure cycle (three re-uses were conducted). $\mathrm{KHCO}_{3}$ elution $+\mathrm{NaOH}$ rinse were used to remove uranium and organic matter from braids before re-uses.

As shown in Figure 15, both braids have nearly $100 \%$ recovery in uranium adsorption capacity in the first re-use, but recovery dropped for both cycle times starting with the $2^{\text {nd }}$ re-use. In general, the braid that was exposed for a 42-day cycle had a lower \% recovery in each re-use cycle compared to the braid that was exposed for a 28 day cycle. This result supports the hypothesis that the longer the seawater exposure cycle, the lower the recovery of uranium capacity for each adsorbent re-use.

To gain more insight into the effect of seawater exposure time, the recoveries of uranium adsorption capacity of the two ORNL AI8 braids were compared relative to cumulative seawater exposure time (Figure 16). Both braids showed linear decrease in recovery of uranium capacity after the first re-use. Interestingly, under the same cumulative seawater exposure time, the braid with the 42-day exposure cycle shows higher recovery than the braid with the 28-day cycle. For example, at 84 days cumulative seawater exposure, the braid with 42-day exposure cycle (one reuse) has $97 \pm 3 \%$ of recovery, but the braid with 28-day exposure cycle (two re-uses) has $78 \pm$ $9 \%$ of recovery. This suggests that the shorter-term seawater exposure does not benefit the overall capacity recovery of adsorbent. Since the shorter-term seawater exposure is associated with higher re-use frequency of the braid, it is possible that the capacity recovery is affected by the number of re-uses, not the total seawater exposure time.

FT-IR observations of the experiment suggest that the braid leaching processes didn't cause significant degradation of the amidoxime ligands (Table 3). Furthermore, the intensities of the FT-IR signature peak at $928 \mathrm{~cm}^{-1}(\mathrm{~N}-\mathrm{O}$ stretching) indicate that the braid with the 28-day 
exposure cycle still had a higher percentage of remaining $\mathrm{N}-\mathrm{O}$ peak compared to the 42-day exposure cycle counterpart at any given time point (Figure 17).

The disagreement between percentage of remaining amidoxime ligands and the recovery of uranium capacity from the comparison of the two ORNL AI8 braids is puzzling. It appears that the abundance of amidoxime ligand alone can't explain the performance of uranium adsorbents. As such, it is also not possible to identify a threshold of amidoxime abundance to determine the reusability of the adsorbent. Our results demonstrate the complexity of reusability of uranium adsorbent in real seawater. The adsorbent reusability may be a function of many factors such as amidoxime stability in seawater (this study), physical properties of adsorbents (Pan et al., 2015), organic matter adsorption, biofouling, interferences from other competing ions, and the adsorbent types, etc.

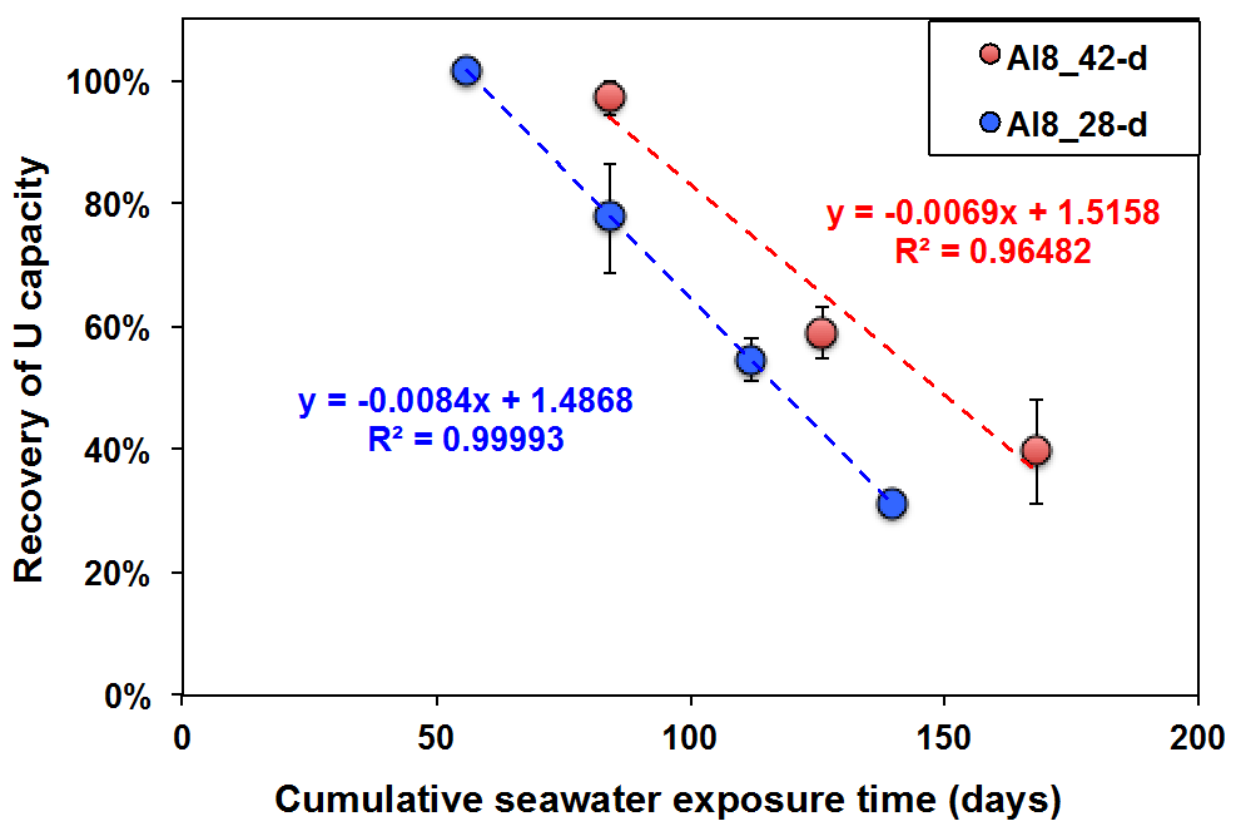

Figure 16. Recovery of uranium adsorption capacity as a function of cumulative seawater exposure time of two ORNL AI8 braids. One adsorbent was on a 28-day seawater exposure cycle and the other was on a 42-day seawater exposure cycle. $\mathrm{A}_{\mathrm{KHCO}}$ elution $+\mathrm{NaOH}$ rinse was used to remove uranium and organic matter from the braids before re-use. 
PNNL-25874

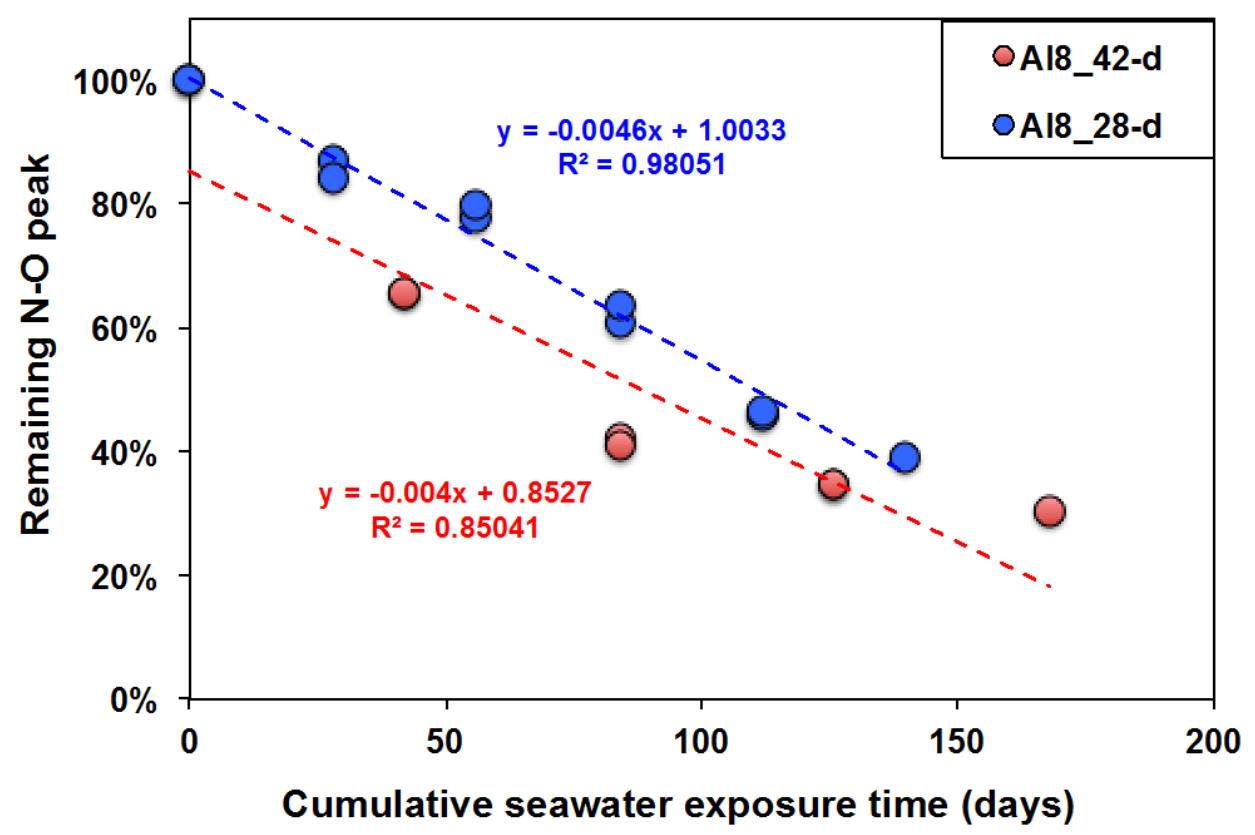

Figure 17. Percentage of peak intensity of $928 \mathrm{~cm}^{-1}$ (N-O stretching) from FT-IR as a function of cumulative seawater exposure time of two ORNL AI8 braids. One adsorbent was on a 28-day seawater exposure cycle and the other was on a 42-day seawater exposure cycle. $\mathrm{A} \mathrm{KHCO}_{3}$ elution $+\mathrm{NaOH}$ rinse was used to remove uranium and organic matter from the braids before re-use.

\subsubsection{Simultaneous Reusability Test with Three Different Amidoxime-based Adsorbent Formulations}

We specifically tested the reusability of braids with different adsorbent formulations. Three ORNL braids with different formulations, AI8, AF8, and AF1-DMSO, were used in this test. All three braids were tested in the same seawater flume with a 28-day seawater exposure cycle. The major difference between the three braids is the comonomer used. The AI series adsorbents have vinylphosphonic acid comonomer; while the AF series adsorbents have an itaconic acid comonomer (Das et al., 2016a,b). The difference between the AF8 and AF1-DMSO is on different monomer/comonomer mol ratios (Das et al., 2016b).

The comparison of recovery of uranium adsorption capacity from re-use for three different formulations of amidoxime-based adsorbents is shown in Figure 18. The AI8 formulation had the best adsorption capacity upon multiple re-use. In the first re-use, the AF8 braid's capacity recovery (97 $\pm 1 \%$ ) was comparable to that of AI8, but the AF1-DMSO's recovery was only $79 \pm 4 \%$. In the $2^{\text {nd }}$ re-use, both AF8 and AF1-DMSO braids' recovery (49 $\pm 2 \%$ and $55 \pm 6 \%$, respectively) were significantly less than that for the AI8 braid (78 $\pm 9 \%)$. These results indicate that reusability indeed is related to adsorbent formulation. Although AF8 adsorbent has good recovery in the first re-use, it also shows marked decrease of capacity recovery in the $2^{\text {nd }}$ re-use, the same as AI8 adsorbent. 
PNNL-25874

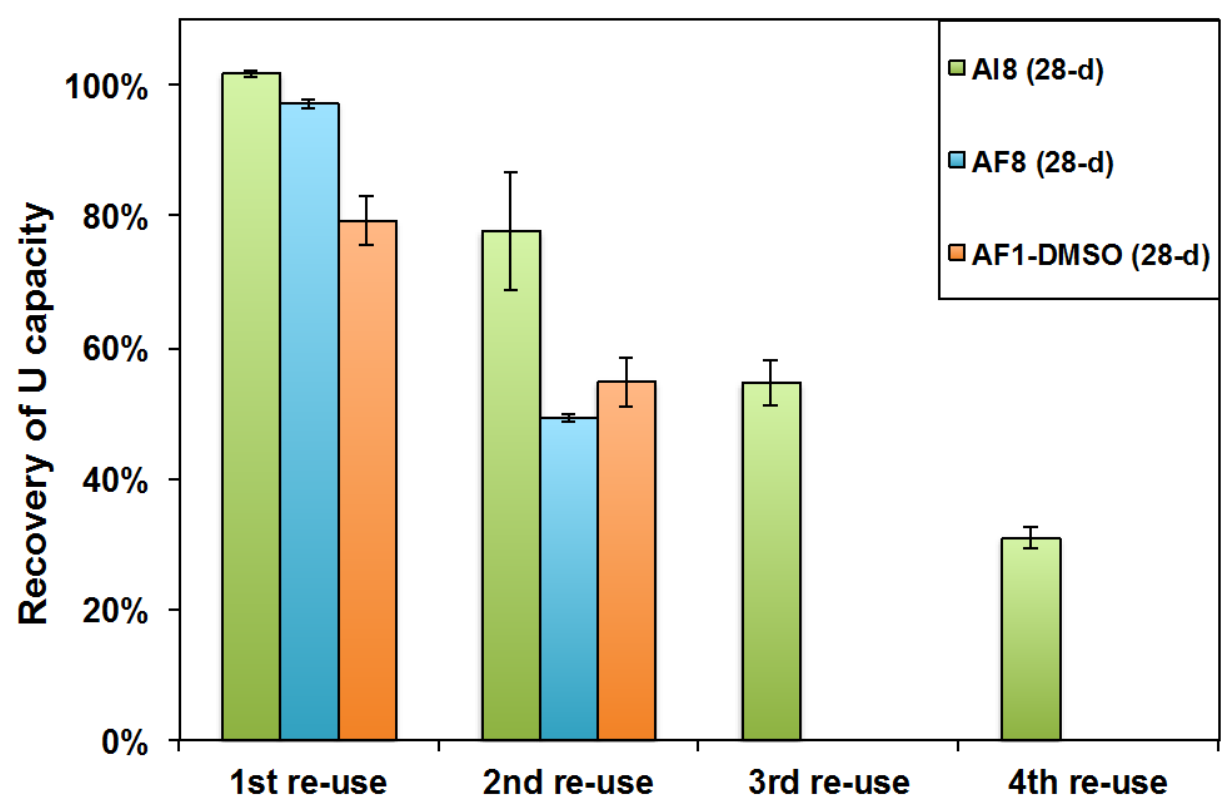

Figure 18. Comparison of recovery of uranium adsorption capacity of three ORNL braids with different formulations (AI8, AF8, AF1-DMSO) in multiple re-uses. All three braids were tested simultaneously using a 28-day seawater exposure cycle.

\subsection{Total Harvestable Uranium}

The ultimate goal of reusing an adsorbent is to harvest the highest quantity of uranium during the lifetime of the adsorbent or "total harvestable uranium". Determination of total harvestable uranium is another means to assess what deployment strategy will yield the maximum amount of uranium before the adsorbent performance is exhausted. Total harvestable uranium is determined by summing the total mass of uranium obtained per kg of adsorbent (i.e. an adsorption capacity, g U/kg adsorbent) for each deployment. For example, for a braid re-used three times, the total harvestable uranium is the summation of adsorption capacities from the initial exposure, the first, the second and the third re-uses.

As shown in Figure 19, the ORNL AI8 braid with a 28-day exposure cycle reached 10g of harvestable uranium in 140 days. The AI8 braid on a 42-day exposure cycle took about 20 additional days to reach the same mass of total harvestable uranium. This comparison of cycle times suggests that a higher amount of uranium can be extracted with a shorter seawater exposure cycle (higher re-use frequency). 


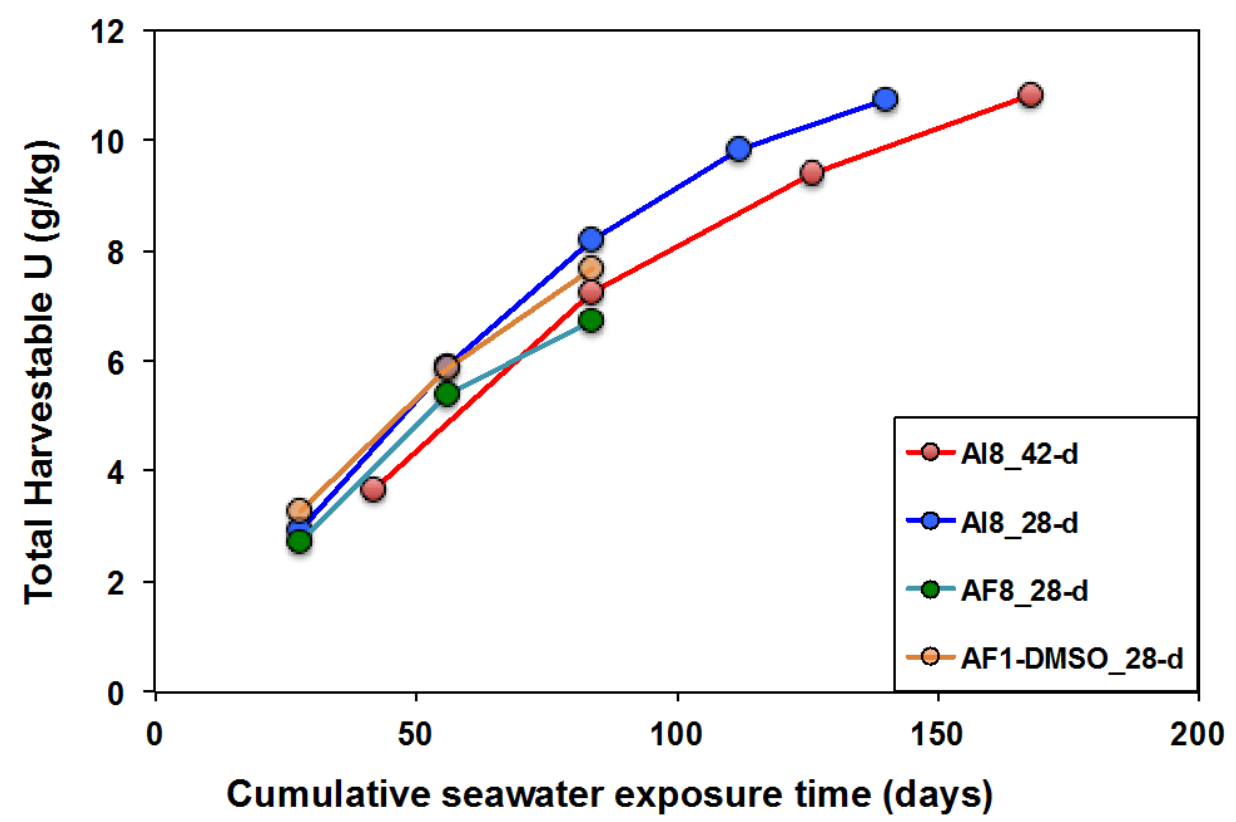

Figure 19. Total harvestable uranium $(\mathrm{g} / \mathrm{kg})$ vs. cumulative seawater exposure time of four ORNL braided adsorbents, different in formulation (AI8, AF8, AF1-DMSO) or seawater exposure cycle (28 days and 42 days. The total harvestable uranium is a cumulative adsorbed uranium from each seawater deployment.

It is important to note that this exposure time cycle assessment dies not consider the costs associated with the deployment strategy. While a 28-day exposure cycle may harvest more uranium in a shorter time, it also requires more re-uses than the 42-day exposure cycle and thus is likely to be more costly in the operation/logistics. However, novel adsorbent deployment/elution processes such as a symbiotic offshore energy harvest system (Slocum, 2015) may significantly reduce the cost of operation/logistics and thus favor the short-term cycle/high frequency re-use approach.

It is also important to note that the exposure tests in our study were all in $0.45 \mu \mathrm{m}$ filtered seawater, which greatly reduced the occurrence of biofouling. Park et al. (2016) have demonstrated that biofouling can have a significant impact on the ability of an adsorbent to sequester uranium from seawater. Since biomass accumulation is a function of seawater exposure time, the shorter seawater exposure cycle is preferable for avoiding the significant biofouling accumulation and its negative effect on uranium adsorption.

Finally, we also compared the total harvestable uranium in three different ORNL adsorbents (AI8, AF8, AF1-DMSO) (Figure 19). In 84 days cumulative seawater exposure, the total harvestable uranium performance is AI8>AF1-DMSO>AF8. In 84 days, the AF8 braid with 28day exposure cycle has less total harvestable uranium than the AI8 braid with 42-day exposure 
cycle. These results again suggest that performance of uranium harvest by reusing adsorbent is affected by adsorbent types.

\subsection{Summary and Conclusions}

In our last adsorbent reusability report, we identified that $\mathrm{KHCO}_{3}$ elution is a green, cost efficient way to strip uranium from ORNL amidoxime-based polymeric adsorbents. In this report we further identified that the addition of $0.5 \mathrm{M} \mathrm{NaOH}$ rinse step after $\mathrm{KHCO}_{3}$ elution can remove the organic matter adsorbed on adsorbents and significantly reduce the negative impact from natural organic matter coating on re-use efficiency of adsorbents during long-term real seawater exposure. Using $\mathrm{KHCO}_{3}$ elution $+\mathrm{NaOH}$ rinse approach, for the first time, we can achieve near $100 \%$ recovery of uranium adsorption capacity. FT-IR signatures of adsorbents before and after $\mathrm{KHCO}_{3}$ elution $+\mathrm{NaOH}$ rinse show that no significant change in the surface functionality of adsorbents, indicating that $\mathrm{KHCO}_{3}$ elution $+\mathrm{NaOH}$ rinse is a very mild uranium stripping method and didn't cause damage on the adsorbents.

The further re-uses of ORNL adsorbents show decrease of capacity recovery after the first reuse. Multiple lines of evidence (FT-IR signatures, $\mathrm{Ca} / \mathrm{U}$ and $\mathrm{Mg} / \mathrm{U}$ ratios) suggest that the potential cause of decrease in recovery is degradation of amidoxime ligands during seawater exposure. The mechanism of amidoxime ligands in real seawater is still unclear at this point. It can be chemical or biological degradations or the combination of both. But this observation points to the potential negative effect from prolonged seawater exposure.

The comparisons of capacity recovery between two ORNL AI8 braids with different seawater exposure cycles (28 and 42 days) show that adsorbent with shorter seawater exposure cycle has better recovery in uranium capacity after re-use. However, on the basis of cumulative exposure time, the braid with short seawater exposure cycle didn't show better capacity recovery than the braid with long seawater exposure time, although FT-IR signatures do reveal that the braid with long seawater exposure time has more amidoxime ligands degraded. Therefore, the abundance of amidoxime ligand alone can't be used to assess the performance of adsorbents in seawater uranium adsorption. As we also observed that different adsorbent formulations have different reusability performance, we conclude that adsorbent reusability is a function of multiple factors such as amidoxime stability in seawater, physical properties of adsorbents, interaction with natural organic matter, biofouling, interferences from other competing ions, and the adsorbent types, etc.

Performances of adsorbents with multiple re-uses were further evaluated by their total harvestable uranium. Results of this analysis suggest that uranium adsorbent with shorter seawater exposure cycle (higher re-use frequency) can yield higher total harvestable uranium in a shorter time compared to the same adsorbent with longer seawater exposure cycle (lower re-use 
frequency). The performance of total harvestable uranium also varies with different adsorbent formulations, suggesting that development of novel adsorbents with high capacity and durability is critical. While the results of this analysis favor the short seawater exposure cycle, other factors such as costs in operation/adsorbent deployment and recover from ocean, as well as biofouling in unfiltered seawater still have to be considered in the cost analysis.

\subsection{References}

DOE (2010). Nuclear Energy Research and Development Roadmap: Report to Congress; U.S. Department of Energy: Washington, D. C., 2010. Report available at: http://www.energy.gov/ne/downloads/nuclear-energy-research-and-development-roadmap

Das, S., Oyola, Y., Mayes, R. T., Janke, C. J., Kuo, L.-J., Gill, G., Wood, J. R., Dai, S. (2016a) Extracting Uranium from Seawater: Promising AI Series Adsorbents. Ind. Eng. Chem. Res. 55, 4103-4109.

Das, S., Oyola, Y., Mayes, R. T., Janke, C. J., Kuo, L.-J., Gill, G., Wood, J. R., Dai, S. (2016b) Extracting Uranium from Seawater: Promising AF Series Adsorbents. Ind. Eng. Chem. Res. 55, 4110-4117.

Das, S., Brown, S., Mayes, R. T., Janke, C. J., Tsouris, C., Kuo, L. J., Gill, G., Dai, S. (2016c) Novel poly(imide dioxime) sorbents: Development and testing for enhanced extraction of uranium from natural seawater. Chem. Eng. J., 298, 125-135.

Gill G.A., L-J Kuo, J.E. Strivens, J.R. Wood, C.M. Wai, and H-B Pan (2015) Investigations into Alternative Desorption Agents for Amidoxime-Based Polymeric Uranium Adsorbents. PNNL-24378, Pacific Northwest National Laboratory, Richland, WA.

Gill, Gary A., Li-Jung Kuo, Chris J. Janke, Jordana R. Wood, Richard T. Mayes, Costas Tsouris, Yatsandra Oyola, Jonathan E. Strivens, Michael Cobb , George Bonheyo , Robert Jeters, Jiyeon Park, Tarang Khangaonkar, R. Shane Addleman, Wilaiwan Chouyyok, Marvin Warner, Sonja Peterson, David G. Abrecht, Sadananda Das, Ken Buesseler, Crystal Breier, Evan D'Alessandro, Horng-Bin Pan and Chien Wai (2016). The Uranium from Seawater Program at PNNL: Overview of Marine Testing, Adsorbent Characterization, Adsorbent Durability, Adsorbent Toxicity, and Deployment Studies. Ind. Eng. Chem. Res. 55, 42644277.

Janke, C. J., S. Dai, and Y. Oyola, US Pat., 2012-13553288, 20130071659, 2013.

Kang, S. O., Vukovic, S., Custelcean, R., Hay, B. P. (2012) Cyclic Imide Dioximes: Formation and Hydrolytic Stability. Ind. Eng. Chem. Res. 51, 6619-6624.

Kim, J., C. Tsouris, Y. Oyola, R. Mayes, C. Hexel, C. Janke and S. Dai (2013) Nucl. Eng. Int., 2013, 58, 34-35 
Kim, J.; Tsouris, C.; Oyola, Y.; Janke, C. J.; Mayes, R. T.; Dai, S.; Gill, G.; Kuo, L.-J.; Wood, J.; Choe, K.-Y.; Schneider, E.; Lindner, H. (2014) Uptake of Uranium from Seawater by Amidoxime-Based Polymeric Sorbent: Field Experiments, Modeling, and Updated Economic Assessment. Ind. Eng. Chem. Res. 53, 6076-6083

Kuo, Li-Jung, Christopher Janke, Jordana R. Wood, Jonathan E. Strivens, and Gary A. Gill (2016). Characterization and Testing of Amidoxime-Based Adsorbent Materials to Extract Uranium from Natural Seawater. Ind. Eng. Chem. Res. 55 (15), 4285-4293.

Lindner, Harry and Erich Schneider (2015). Review of cost estimate for uranium recovery from seawater. Energy Economics 49, 9-22.

Schneider, E., Sachde, D. (2013) The cost of recovering uranium from seawater by a braided polymer adsorbent system. Science \& Global Security 21, 134-163.

Seko, N., A. Katakai, M. Tamada, T. Sugo and F. Yoshii (2005). Fine Fibrous Amidoxime Adsorbent Synthesized by Grafting and Uranium Adsorption-Elution Cyclic Test with Seawater. Separation Science and Technology, 39 (16): 3753-3767.

Pan, H.B., W.S. Liao, C.M. Wai, Y. Oyola, C.J. Janke, G.X. Tian, and L.F. Rao (2014) Carbonate-H2O2 leaching for sequestering uranium from seawater. Dalton Trans. 43, 10713-10718.

Pan, H.-B., Kuo, L.-J., Wood, J., Strivens, J., Gill, G. A., Janke, C. J., Wai, C. M. (2015) Towards Understanding $\mathrm{KOH}$ Conditioning of Amidoxime-based Polymer Adsorbents for Sequestering Uranium from Seawater. RSC Advances 5, 100715-100721.

Pan, H.-B., Kuo, L.-J., Wai, C. M., Miyamoto, N., Joshi, R., Wood, J. R., Strivens, J. E., Janke, C. J., Oyola, Y., Das, S., Mayes, R. T., Gill, G. A. (2016a) Elution of Uranium and Transition Metals from Amidoxime-Based Polymer Adsorbents for Sequestering Uranium from Seawater. Ind. Eng. Chem. Res. 55, 4313-4320.

Pan, H.-B., Wai, C. M., Kuo, L.-J., Gill, G. A., Tian, G.X., Rao, L., Das, S., Mayes, R. T., Janke, C. J. (2016b) Bicarbonate Elution of Uranium from Amidoxime-based Polymer Adsorbents for Sequestering Uranium from Seawater. Unpublished document.

Park, J., Gill, G.A., Strivens, J.E., Kuo, L-J, Jeters, R.T., Avila, A., Wood, J.R., Schlafer, N.J., Miller, E.A., Addleman, R.S., Bonheyo, G.T. (2016) Effect of biofouling on the performance of amidoxime-based polymeric uranium adsorbents. Ind. Eng. Chem. Res. 55, 4328-4338.

Shimizu, T. and M. Tamada (2004) Practical scale system for uranium recovery from seawater using braid type adsorbent. Proceedings of Civil Engineering in the Ocean 20, 617-622.

Slocum, Alexander H. (2015) Symbiotic offshore energy harvesting and storage systems. Sustainable Energy Technologies and Assessments 11, 135-141. 
Suzuki, T., K. Saito, T. Sugo, H. Ogura and K. Oguma (2000). Functional elution and determination of uranium and vanadium adsorbed on amidoxime fiber from seawater. Analytical Sciences 16, 429-432.

Wood, Jordana, R., Gary A. Gill, Li-Jung Kuo, Jonathan E. Strivens and Key-Young Choe (2016) Comparison of Analytical Methods for the Determination of Uranium in Seawater using Inductively Coupled Plasma Mass Spectrometry. Ind. Eng. Chem. Res. 55, 4344-4350. 


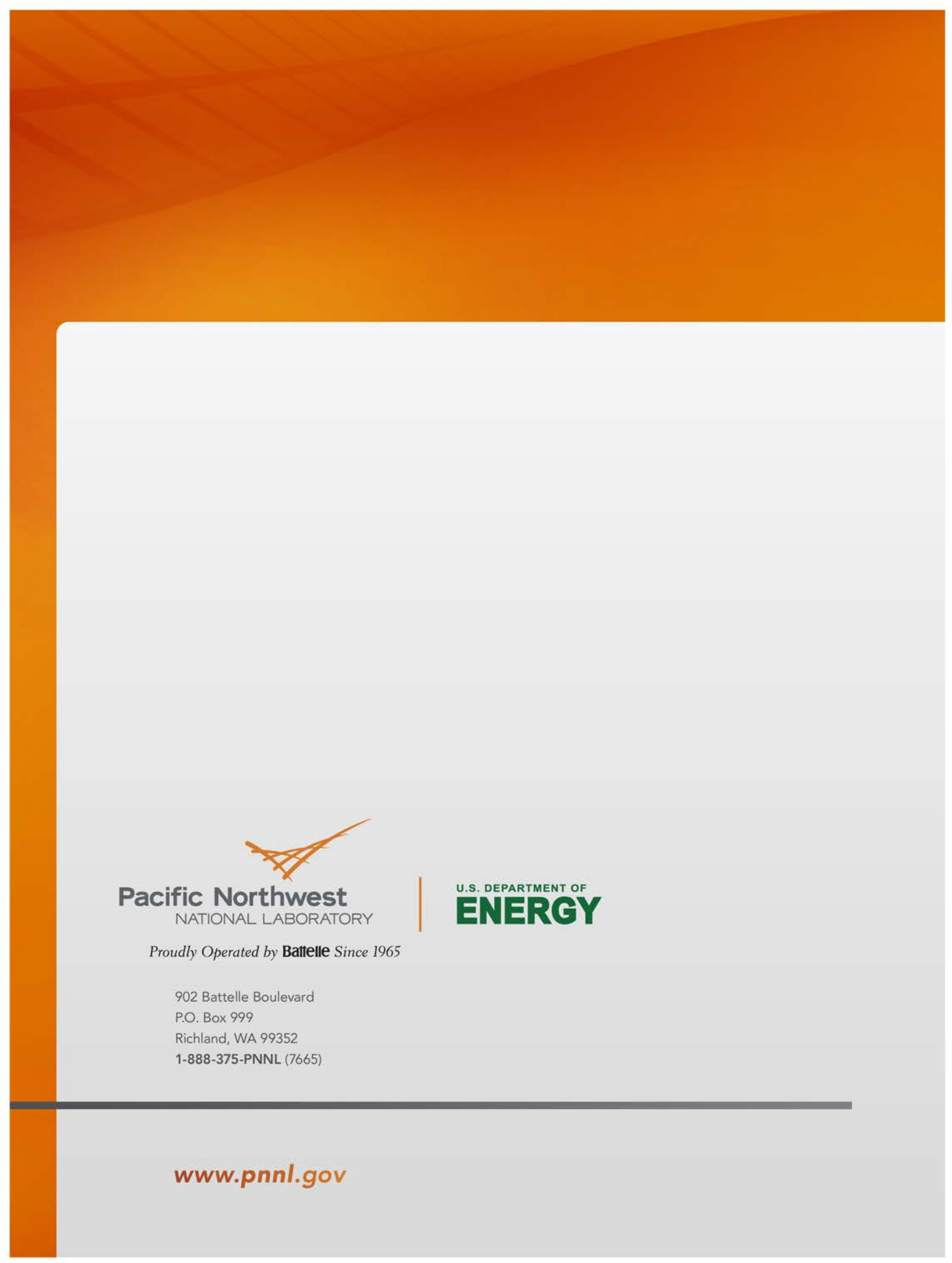

